\title{
Changing water cycle and freshwater transports in the Atlantic Ocean in observations and CMIP5 models
}

\author{
Nikolaos Skliris ${ }^{1}$ (D) Robert Marsh ${ }^{1} \cdot$ Jennifer V. Mecking ${ }^{2} \cdot$ Jan D. Zika ${ }^{3}$
}

Received: 4 September 2019 / Accepted: 23 April 2020 / Published online: 5 May 2020

(c) The Author(s) 2020

\begin{abstract}
Observations over the last 40 years show that the Atlantic Ocean salinity pattern has amplified, likely in response to changes in the atmospheric branch of the global water cycle. Observational estimates of oceanic meridional freshwater transport $(F W T)$ at $26.5^{\circ} \mathrm{N}$ indicate a large increase over the last few decades, during an apparent decrease in the Atlantic Meridional Overturning Circulation (AMOC). However, there is limited observation based information at other latitudes. The relative importance of changing $F W T$ divergence in these trends remains uncertain. Ten models from the Coupled Model Intercomparison Project Phase 5 are analysed for AMOC, FWT, water cycle, and salinity changes over 1950-2100. Over this timescale, strong trends in the water cycle and oceanic freshwater transports emerge, a part of anthropogenic climate change. Results show that as the water cycle amplifies with warming, $F W T$ strengthens (more southward freshwater transport) throughout the Atlantic sector over the 21st century. FWT strengthens in the North Atlantic subtropical region in spite of declining $A M O C$, as the long-term trend is dominated by salinity change. The $A M O C$ decline also induces a southward shift of the Inter-Tropical Convergence Zone and a dipole pattern of precipitation change over the tropical region. The consequent decrease in freshwater input north of the equator together with increasing net evaporation lead to strong salinification of the North Atlantic sub-tropical region, enhancing net northward salt transport. This opposes the influence of further $A M O C$ weakening and results in intensifying southward freshwater transports across the entire Atlantic.
\end{abstract}

Keywords Ocean freshwater transports $\cdot$ Freshwater budget $\cdot$ Water cycle $\cdot$ Salinity $\cdot$ Atlantic Ocean $\cdot$ CMIP5

\section{Introduction}

Net evaporation over the Atlantic Ocean provides the source of moisture that is exported to the Pacific, principally via the trade winds and makes the Atlantic more saline than other ocean basins, most notably the Pacific Ocean. Water vapour losses to the atmosphere are mainly balanced by a pattern of generally southward ocean meridional freshwater transport

Electronic supplementary material The online version of this article (https://doi.org/10.1007/s00382-020-05261-y) contains supplementary material, which is available to authorized users.

Nikolaos Skliris

N.Skliris@noc.soton.ac.uk

1 Ocean and Earth Science, University of Southampton, Southampton, UK

2 National Oceanography Centre, Southampton, UK

3 School of Mathematics and Statistics, University of New South Wales, Sydney, Australia
(FWT) throughout the Atlantic sector. These atmospheric and oceanic freshwater pathways are an intrinsic part of the global water cycle, a central component of the climate system, which is likely to change dramatically under global warming. Thermodynamics dictate that the atmospheric branch of the global water cycle will amplify in a warming climate with dry regions getting drier and wet regions getting wetter, an effect moderated by changes in the atmospheric circulation (Held and Soden 2006). Over the ocean the water cycle amplitude is defined by the surface net freshwater flux [Precipitation $(P)+$ River runoff $(R)+$ Ice Melting $(I M)$ - Evaporation $(E)$ - Ice Formation $(I F)]$. It is very difficult to estimate long-term changes in $E$ and $P$ from direct measurements over the ocean (Hegerl et al. 2015). In contrast, the ocean salinity 3-D field, a well-measured parameter over the last few decades, is considered to be an integrator of surface freshwater flux change, and it is often used to indirectly estimate long-term changes in the global water cycle (Helm et al. 2010; Durack et al. 2012; Skliris et al. 2016; Zika et al. 2018). The spatial pattern of global ocean surface 
salinity change since 1950 provides strong evidence for an amplified water cycle with precipitation-dominated oceanic regions such as the tropical and subpolar regions becoming less saline, and evaporation-dominated regions such as the subtropical gyres becoming saltier (Helm et al. 2010; Durack and Wijffels 2010; Skliris et al. 2014). Recent studies inferring water cycle changes from salinity change indicate a global water cycle amplification of $2-4 \%$ over the last 50-60 years (Durack et al. 2012; Skliris et al. 2014, 2016, Zika et al. 2018). Sub-surface observations since the 1950's also clearly show an accentuation of the Atlantic-Pacific salinity contrast with strongest salinity increases obtained throughout the upper layer of the tropical/subtropical Atlantic (Skliris et al. 2014). Terray et al. (2012) showed that the increased tropical/subtropical Atlantic-Pacific surface salinity contrast from the early 1970s to late 2000s significantly exceeded internal natural variability in climate model control simulations, suggesting that the emerging trend could be due to anthropogenic climate change.

Water cycle and $F W T$ changes in the Atlantic Ocean are of critical importance for the global thermohaline circulation and climate. In a steady state, divergence of ocean freshwater transport balances area-integrated surface net freshwater flux. Warming-driven amplification of the water cycle over the Atlantic Ocean and increasing freshwater inputs from the Arctic (mainly due to accelerating ice sheet and multi-year sea ice melt) are expected to lead to increasing (southward) $F W T$ across the Atlantic sector. On the other hand, $F W T$ is also intrinsically associated with the Atlantic Meridional Overturning $(A M O C)$, in turn favoured by relatively high surface salinity in mid-high latitudes. Changes in $F W T$ divergence and in the water cycle amplitude in the northern North Atlantic strongly affect the freshwater content in this area which in turn controls deep water formation and thus the AMOC strength. McDonagh et al. (2015) showed a very strong correlation between southward $F W T$ and $A M O C$ strength based on their 8.5-year observational time series (2004-2013) at $26.5^{\circ} \mathrm{N}$. Based on historical analyses of observations at $24.5^{\circ} \mathrm{N}$ they also showed that southward $F W T$ has largely increased i.e. by $\sim 0.34 \mathrm{~Sv}$ between 1974 and their 8.5-year timeseries (2004-2012) at $26.5^{\circ} \mathrm{N}$. They attributed the southward $F W T$ increase to an intensification of the oceanic water cycle north of $26.5^{\circ} \mathrm{N}$. But with limited information at other latitudes, relative importance of changing $F W T$ divergence and its impact on the freshwater budget of the Atlantic remain uncertain.

Atlantic $F W T$ is typically divided into two main contributors: the freshwater transport by the AMOC (i.e. the contribution from zonally averaged meridional mass transport multiplied by zonally averaged salinity), often referred to as $M_{o v}$ (or $F_{o v}$ ), and the remaining azonal or gyre contribution to freshwater transport, often referred to as $M_{a z}$ (or $F_{a z}$ ) (de Vries and Weber 2005). While $M_{o v}$ and $M_{a z}$ were originally defined at the southern boundary of the Atlantic the same definition can be used at all latitudes. In the long term response to an extremely weakened $A M O C$ changes in $M_{o v}$ have been shown to be dominated by changes in the zonal mean velocity field, while changes in $M_{a z}$ are mainly set by changes in salinity (Mecking et al. 2016). Across the tropical and subtropical North Atlantic, a weak $A M O C$ tends to induce an anomalous southward $M_{o v}$ while changes in $M_{a z}$ have the opposite sign (more northward fresh water transport; Mecking et al. 2016).

Although Coupled Model Intercomparison Project (CMIP) projections over the 21st century show a large amplification of the water cycle with warming (Durack et al. 2012; Skliris et al. 2016) they also show a large reduction in AMOC strength (Schleussner et al. 2014) which in turn may counteract the impact of water cycle change on FWT. As the water cycle intensifies $M_{o v}$ is expected to tend towards zero with decreasing $A M O C$ while $M_{a z}$ is expected to increase in the subtropical North Atlantic with increasing salinity. The relative importance of changes in these two opposing contributions will control $F W T$ divergence in the Atlantic and, together with warming-driven accelerating local water cycle and freshwater inputs from the polar regions, will determine how the freshwater budget of the Atlantic and the global thermohaline circulation will change in the future.

$M_{O V}$ is also used as an indicator for the AMOC stability, with severe implications for the global climate. In particular, the sign of $M_{o v}$ at the southern boundary of the Atlantic Ocean at $34^{\circ} \mathrm{S}$ is associated with the stability regime of the overturning. A positive $M_{o v}$ value at $34^{\circ} \mathrm{S}$ (i.e. when the $A M O C$ imports freshwater into the Atlantic) is linked to a mono-stable $A M O C$ regime, implying no possible transition from a stable $A M O C$ on-state (i.e. the present day $A M O C$ ) to a stable $A M O C$ off-state (i.e. a very weak or even collapsed $A M O C$ ), whilst a negative $M_{o v}$ value (i.e. when the $A M O C$ exports freshwater from the Atlantic) is linked to a bi-stable regime allowing a transition to a stable $A M O C$ off-state (Huisman et al. 2010). When AMOC is collapsing $M_{o v}$ will tend to zero, so if on-state $M_{o v}$ is positive (negative) at the southern boundary this will create an anomalous salt import (export) into (from) the Atlantic leading to the destabilisation (stabilisation) of the AMOC off state. Recent observational estimates support a negative $M_{o v}$ at the southern boundary of the Atlantic (Bryden et al. 2011; Garzoli et al. 2013), suggesting that the present day AMOC resides in the bi-stable regime.

In this study we investigate changes in the freshwater budget of the Atlantic Ocean as observed over the last 40 years (1979-2018) and in 10 CMIP5 model historical and 21 st century (2006-2100) simulations based on two Representative Concentration Pathways (RCP) scenarios: an intermediate greenhouse-gas mitigation scenario (RCP4.5) and an unmitigated climate change scenario with continued 
high greenhouse-gas emissions (RCP8.5). We focus on how $F W T$ changes across the Atlantic sector with respect to the changing water cycle and $A M O C$ in the CMIP5 simulations. We distinguish between $A M O C$-driven $\left(M_{o v}\right)$ and mainly salinity-driven azonal $\left(M_{a z}\right)$ transport contributions to changing $F W T$. Implications of the changing water cycle and freshwater transports to the future stability of the overturning are also discussed.

\section{Data and models}

We chose the 1979-2018 period to investigate recent observed changes in the freshwater/salt budget of the Atlantic Ocean as the reconstruction of salinity and surface water flux $(E, P)$ fields is better constrained by in situ observations and satellite-derived data, respectively, allowing for a more accurate analysis of their variability at inter-annual/ decadal scales. Prior to the satellite era (i.e. before 1979) re-analysis based $E$ and $P$ fields are poorly constrained by observations with too low confidence in representing variability and trends (Skliris et al. 2014).

\subsection{Salinity observational data}

The inter-annual variability and trend of salinity over 1979-2018 is assessed here using the UK Met Office Hadley Centre Enhanced Ocean Data Assimilation and Climate prediction (ENACT) archive version4 (En4, subversion En4.2.1) dataset (https://www.metoffice.gov.uk/hadobs/en4/ download-en4-2-1.html) developed by Good et al. (2013). It consists of quality-controlled temperature and salinity (PSS78) profiles with original data sources including the World Ocean Database (2005), the Global Temperature-Salinity Profile Programme (from 1990) and profiling float data from the Argo Global Data Assembly Center (from 1999). A monthly objectively-analysed version of this dataset is used here with a $1^{\circ} \times 1^{\circ}$ horizontal resolution and 42 vertical levels spanning the period 1979-2018.

\subsection{Observational/re-analysis surface freshwater fluxes}

To assess the surface net freshwater flux inter-annual variability and long-term trends, a hybrid product is used spanning the period 1979-2018 in which $E$ is provided by the Objectively Analyzed air-sea Fluxes (OAFlux) dataset (http://rda.ucar.edu/datasets/ds260.1/) (Yu and Weller 2007), that blends NCEP and ECMWF reanalysis products with satellite surface meteorology through an objective synthesis, and $P$ is obtained from the Global Precipitation Climatology Project (GPCP v2.2, http://rda.ucar.edu/datasets/ds728.2/) (Huffman et al. 2009), based on rain gauge observations and satellite retrievals. River runoff into the Atlantic is based on the study of Dai et al. (2009), who found a small (negative) and not statistically significant trend in river discharge averaged over the Atlantic Ocean since the 1950's. Therefore, we only consider here the climatological mean river runoff field in the Atlantic Ocean, assuming no trend over 1979-2018.

\subsection{CMIP5 model simulations}

We analysed the output of the pre-industrial, historical, RCP4.5 and RCP8.5 simulations from ten Coupled Model Intercomparison Project Phase 5 (CMIP5) models (Taylor et al. 2012) comprising ACCESS1.3, CMCC-CM, CNRMCM5, GFDL-ESM2M, HadGEM2-ES, IPSL-CM5A-LR, MPI-ESM-MR, MRI-CGCM3, EC-EARTH, NorESM1-M. The model selection is based on the output availability of three variables: 3-D salinity; 3-D ocean horizontal current velocity; net surface fresh water flux (precipitation + river runoff + ice melting - evaporation - ice formation). From the NCAS British Atmospheric Data Centre we retrieved monthly 3-D salinity, monthly net surface fresh water flux, and monthly horizontal ocean current velocity fields. The periods analysed include a 150 -year period from the preindustrial simulations, 1950-2005 from the historical simulations, and 2006-2100 from the RCP4.5, and RCP8.5 simulations. All models are tested in their pre-industrial control runs and they do not show any statistically significant trend in the amplitude of the water cycle or $F W T$ divergence in the Atlantic Ocean.

\section{Methods}

\subsection{Calculation of $A M O C$ and components of the freshwater budget}

Ten CMIP5 models are analysed for AMOC strength, $F W T$ and its two main components, $M_{o v}$ and $M_{a z}$, surface net freshwater flux and salt content across the Atlantic sector from $34^{\circ} \mathrm{S}$ to $65^{\circ} \mathrm{N}$ over $1950-2100$, historically-forced (1950-2005) and taking RCP4.5 and RCP8.5 scenarios (2006-2100).

$A M O C$ and ocean freshwater transports are computed from ocean current meridional velocity and salinity monthly fields following the mathematical framework described in Mecking et al. (2017).

The AMOC streamfunction is computed as follows:

$\Psi(y, z, t)=\int_{-H}^{z} \int_{E}^{W} \tilde{v}(x, y, z, t) d x d z$ 
where the depth of the ocean is given by $H=H(x, y)$ and $\tilde{v}$ is the meridional velocity with the section mean removed (i.e. $\tilde{v}=v-\bar{v}, \quad \bar{v}=\int_{-H}^{0} \int_{E}^{W} v d x d z / \int_{-H}^{0} \int_{E}^{W} d x d z$ ), and the letters $W$ and $E$ refer to the western and eastern boundaries of the Atlantic Ocean. The freshwater transports due to the $A M O C, M_{o v}$, are computed following de Vries and Weber (2005):

$M_{o v}(y, t)=\frac{-1}{S_{o}(y)} \int_{-H}^{0} \int_{E}^{W} v^{*} S^{*} d x d z$

where the baroclinic component of the zonal mean meridional velocity is given as $v^{*}=\langle v\rangle-\bar{v}$ and the zonal mean meridional velocity is given as $\langle v\rangle=\int_{E}^{W} v d x / \int_{E}^{W} d x$, and likewise for salinity.

The reference salinity is computed as $S_{o}(y)=\int_{-H}^{0} \int_{E}^{W} S d x d z / \int_{-H}^{0} \int_{E}^{W} d x d z$. The meridional velocity used in the computation of $M_{o v}$ is the same as the one used in the computation of the $A M O C$ streamfunction.

The azonal or gyre component of the freshwater transports, $M_{a z}$ is given as follows:

$M_{a z}(y, t)=\frac{-1}{S_{o}(y)} \int_{-H}^{z} \int_{E}^{W} v^{\prime} S^{\prime} d x d z$

where $v^{\prime}=v-\langle v\rangle$ and $S^{\prime}=S-\langle S\rangle$ are the departure from the zonal means.

The total oceanic freshwater transport $(F W T)$ is calculated here as the sum of $M_{a z}$ and $M_{o v}$ at each latitude such that

$F W T=M_{a z}+M_{o v}$

More details about the calculations of $A M O C$ and FWT components in CMIP5 can be found in Mecking et al. (2017).

For the freshwater/salt budget we consider four subregions defined by the sign of area-averaged $P-E+R$ across the Atlantic using the CMIP5 multi-model historical mean meridional distribution (see Fig. 6), namely the North Atlantic sub-polar region $\left(40^{\circ} \mathrm{N}-65^{\circ} \mathrm{N}, P-E+R>0\right)$, the North Atlantic subtropical region $\left(10^{\circ} \mathrm{N}-40^{\circ} \mathrm{N}, P-E+R<0\right)$, the Atlantic tropical region $\left(10^{\circ} \mathrm{N}-7^{\circ} \mathrm{S}, P-E+R>0\right)$, and the South Atlantic subtropical region $\left(34^{\circ} \mathrm{S}-7^{\circ} \mathrm{S}\right.$, $P-E+R<0)$.

The anomalous regional freshwater budget in the CMIP5 RCP 21st century simulations (i.e. with respect to a historical balanced freshwater budget) is defined as:

$\Delta F W=\Delta \iint_{A}(P-E+R) \mathrm{d} A-\Delta[F W T]_{S}^{N}+F W_{r e s}$

where $\Delta F W$ is the change in freshwater content over time, $\Delta \iint_{A}(P-E+R) \mathrm{dA}$ is the change in integrated surface net freshwater flux $(P-E+R)$ over area $A, \Delta[F W T]_{S}^{N}$ is the change in $F W T$ divergence (i.e. $F W T$ at the northern boundary minus $F W T$ at the southern boundary of the region), and $F W_{\text {res }}$ is a residual term mainly expressing the change in freshwater mixing with the adjacent regions, the errors resulting from the choice in time differencing and the nonlinear changes on timescales less than 1 month. For the North Atlantic subtropical region, this term also includes the change in the net freshwater transport at the Gibraltar Strait.

The change in freshwater content $(\Delta F W)$ for the entire Atlantic Ocean and the four sub-regions considered here is inferred from the volume-averaged salinity change using an approximate salt conservation equation:

$\rho_{M}(t) S_{M}(t) V_{M}(t)=\rho_{M}(t+\Delta t) S_{M}(t+\Delta t)\left(V_{M}(t)+\Delta F W\right)$

where $\rho_{M}$ is volume-averaged density $\left(\mathrm{kg} \mathrm{m}^{-3}\right), S_{M}$ is the volume-averaged salinity, $V_{M}$ is the total volume, $t$ is time, $\Delta t$ is an integration time step. $\Delta F W$ is defined as the additional volume of freshwater accumulated or lost over the region over time step $\Delta t$.

\subsection{Timeseries, trends and uncertainty estimates}

We construct monthly anomaly time series for all datasets by subtracting the climatological monthly mean (averages over 1979-2018 for observations and over the last 40 years of the historical simulation for CMIP5) from the monthly data at each grid point. Annual anomalies are then constructed from the monthly anomalies, allowing us to compute linear trends for both observational (1979-2018) and CMIP5 historical (1950-2006) and RCP4.5/8.5 (2006-2100) time-series.

Uncertainties in linear trends are the standard error of a linear fit (least squares). Uncertainties stated concerning CMIP5 ensemble means are the standard deviation of the ensemble (multi-model mean). Uncertainties stated concerning temporal means from observational data (global spatial patterns of surface freshwater fluxes and salinity) or CMIP5 mean uncertainties (i.e. average of individual model uncertainties) are the standard deviation of the yearly detrended timeseries.

\section{Results and discussion}

\subsection{Observed changes over 1979-2018}

\subsubsection{Surface freshwater fluxes}

Figure 1 shows the Atlantic Ocean spatial pattern of 40-year (1979-2018) linear trend in $E-P, E$, and $P$. Although the $E-P$ change spatial pattern indicates an intensifying atmospheric water cycle, the "dry get drier, wet get 

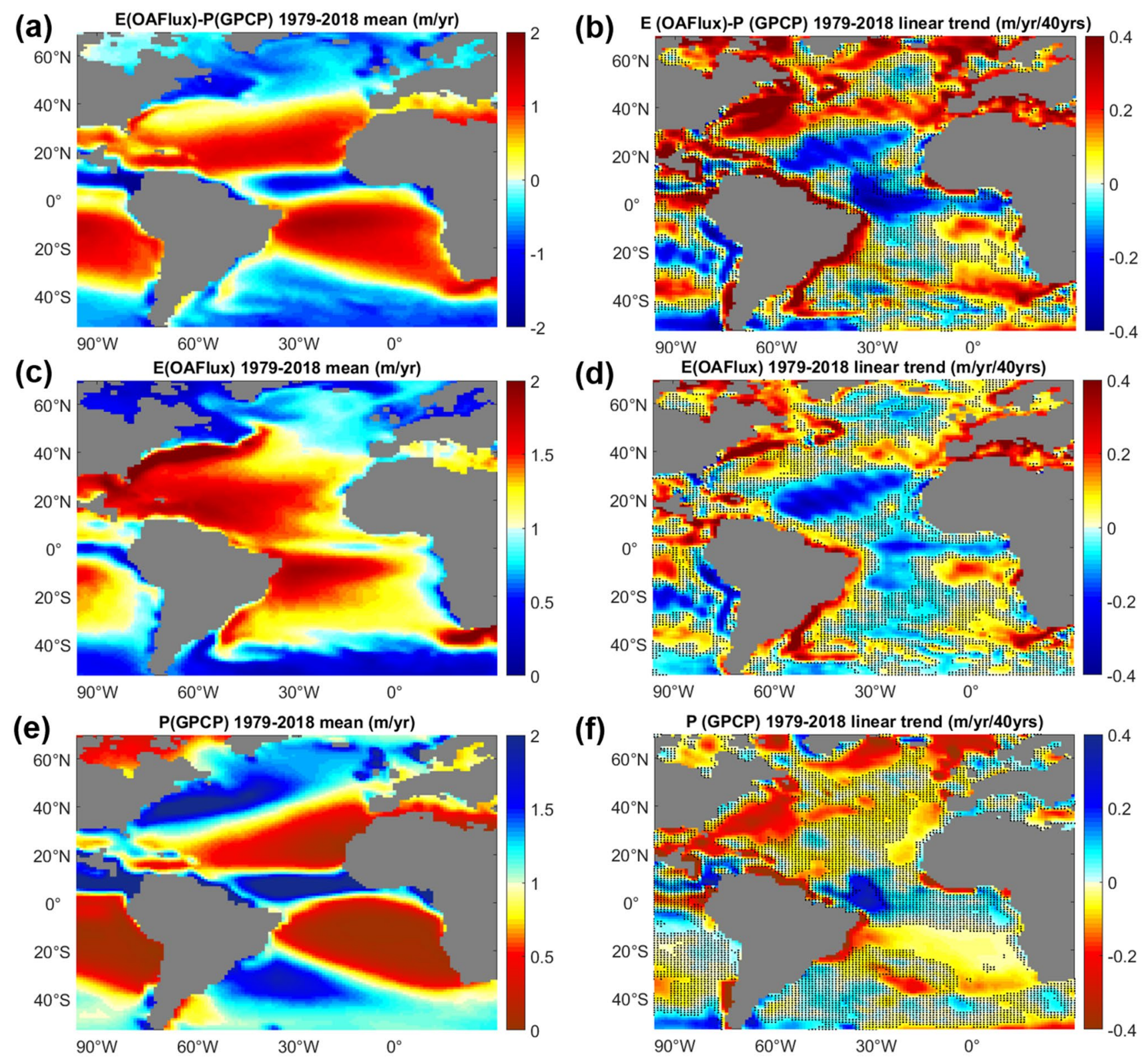

(f)

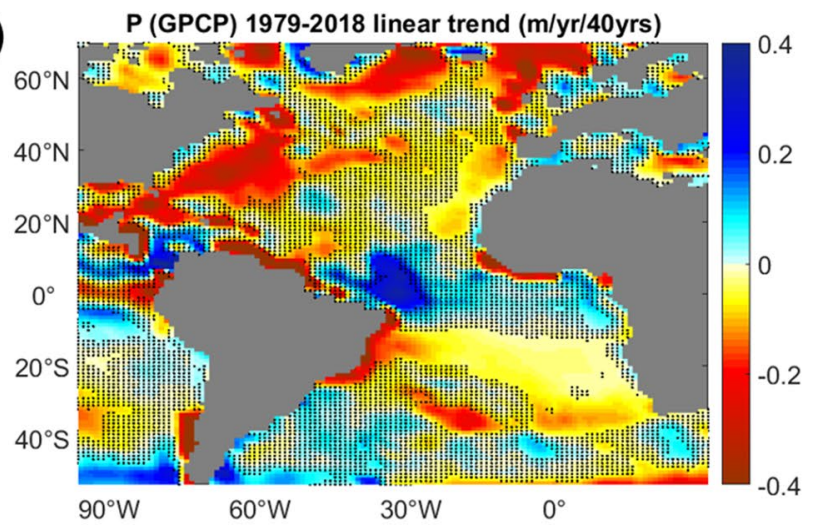

Fig. 1 Spatial patterns of climatological means (month/year) (left panels) and linear trends (month/year/40 years) (right panels) in surface fluxes over 1979-2018. $E-P(\mathbf{a}, \mathbf{b}), E(\mathbf{c}, \mathbf{d}), P(\mathbf{e}, \mathbf{f})$. From

OAFlux $E$ and GPCP $P$. Regions where the linear trend is not significant at the $95 \%$ confidence level are stippled

wetter" paradigm is not evidenced in all regions. Broadscale increases in net evaporation and net precipitation are obtained in the South Atlantic subtropical region and the tropical region, respectively. The North Atlantic subtropical region also shows an overall increased net evaporation but there is no widespread signal as strong net evaporation increases roughly north of $25^{\circ} \mathrm{N}$ are contrasted with net evaporation decreases south of $25^{\circ} \mathrm{N}$. More importantly, the North Atlantic subpolar region shows a broad-scale decrease in net precipitation which is inconsistent with an intensifying water cycle. Results show that net evaporation

over the entire Atlantic Ocean has considerably increased i.e. by $16.7 \pm 8.4 \%$ over $1979-2018$ driven by evaporation increases in the subtropics and broad-scale precipitation decreases everywhere apart from the tropical region. Evaporation increases in the subtropics are in line with increasing surface warming enhancing latent heat fluxes. A significant positive linear trend in evaporation over the Atlantic Ocean attributed to increasing SSTs was also found by Su and Feng (2015), based on various atmospheric re-analysis products over 1979-2011, as well as on the HOAPS satellite-derived product over 1987-2005, and more recently by Craig et al. 
(2017), based on the ERA-Interim re-analysis product over 1979-2014.

Area-averaged $E-P, E$, and $P$ timeseries show large interannual variability but also statistically significant 40 -year trends (at the $95 \%$ confidence interval) in most regions (Fig. 2). $E-P$ fluxes have trended positive in the subtropical regions with net evaporation increase amounting to $8.9 \pm 5.6 \%$ and $8.5 \pm 8.3 \%$ in the subtropics of the South Atlantic and North Atlantic respectively, driven by both increasing $E$ and decreasing $P$.

There is an increase in net precipitation within the tropical convergence zone but the long-term trend is not statistically significant (at the $95 \%$ confidence interval) as strong interannual precipitation anomalies largely dominate variability. The sub-polar North Atlantic shows a strong decrease in net precipitation of $29.5 \pm 5.1 \%$ over 1979-2018 driven by both decreasing $P$ and increasing $E$. Relatively high evaporation rate in the Atlantic sub-polar region (as compared to

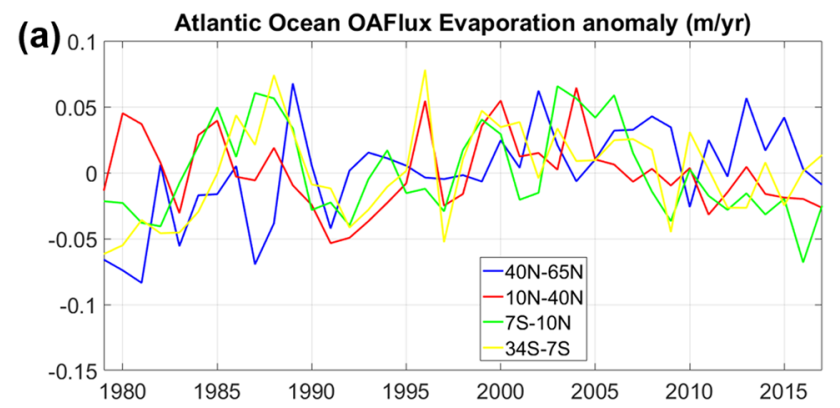

(b)
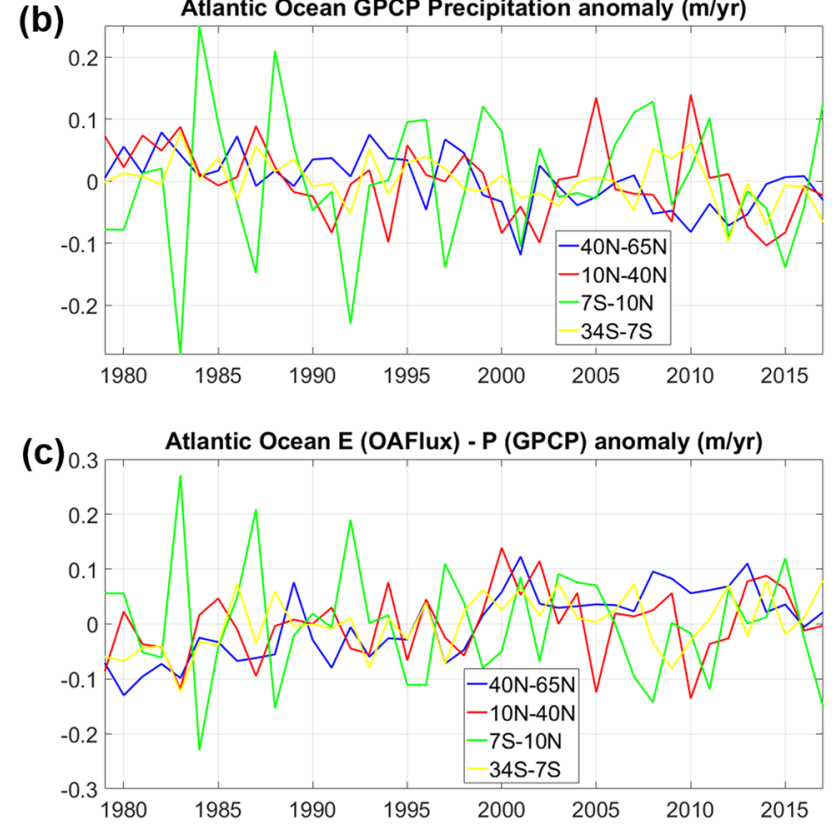

Fig. 2 Annual timeseries (1979-2018) of area-averaged $E-P(\mathbf{a}), E$ (b), and $P(\mathbf{c})$ over the South Atlantic subtropical $\left(34^{\circ} \mathrm{S}-7^{\circ} \mathrm{S}\right.$, yellow), tropical $\left(7^{\circ} \mathrm{S}-10^{\circ} \mathrm{N}\right.$, green), North Atlantic subtropical $\left(10^{\circ}\right.$ $\mathrm{N}-40^{\circ} \mathrm{N}$, red), and sub-polar $\left(40^{\circ} \mathrm{N}-65^{\circ} \mathrm{N}\right.$, blue) regions the Pacific) is associated with higher $S S T s$, in turn associated with $A M O C$-driven northward ocean heat transport (Czaja 2009). Therefore, increasing evaporation in the Atlantic subpolar region obtained here over 1979-2018 may be driven by surface warming which in turn may be associated with a strongly increasing $A M O$ index from negative to positive over this period (Trenberth et al. 2019).

However, strong precipitation decrease over the sub-polar region is not consistent with an intensification of the atmospheric water cycle. A strong correlation is generally found at seasonal timescales between evaporation increase in the central/northern subtropical region and precipitation increase in the sub-polar region of the North Atlantic (Reagan et al. 2018). Therefore, with long-term evaporation increases in the North Atlantic subtropical region, one should expect that a part of this extra moisture would be transported to the subpolar region increasing precipitation there. However, our findings about strong precipitation decrease together with strong salinification of the upper layer suggest on the contrary an overall reduction in surface freshwater flux to the ocean over 1979-2018. This unexpected trend could be due to a change in atmospheric circulation controlling moisture transport and its main pathways over the North Atlantic. Moisture transport from the highly evaporative North Atlantic subtropical to the subpolar region follows two main pathways: a direct pathway that is north-northwestward and an indirect one along the northeastward track of storms in the North Atlantic (Reagan et al. 2018). The latter is highly linked to the North Atlantic Oscillation (NAO) where a positive (negative) NAO phase is linked to a more (less) northward track of storms transporting more (less) moisture to the sub-polar region. However, although there is a decrease in the $N A O$ index over 1979-2018 the linear trend is not statistically significant (at the $95 \%$ confidence interval) and therefore we cannot provide sufficient evidence to attribute the long-term precipitation decrease observed in the sub-polar region to $N A O$ variations.

Except from the sub-polar region, moisture from the strongly evaporative North Atlantic subtropical region is exported to the eastern tropical Pacific through the so-called "Atmospheric Bridge" (Broecker 1997) and to the Atlantic Intertropical Convergence Zone (ITCZ) (Reagan et al. 2018). Subtropical North Atlantic evaporation also provides a moisture source for the African Sahel rainfall (Li et al. 2016). Enhanced moisture transport from the sub-tropical North Atlantic to the Pacific in response to broad-scale warming (Richter and Xie 2010) is consistent with the observed amplification of the surface salinity contrast between the two basins (Terray et al. 2012; Skliris et al. 2014). Also, increasing latent heat flux and surface salinity in the North Atlantic subtropics has been strongly linked to increasing precipitation in the African Sahel after the mid-1980s (Diawara et al. 2016; Li et al. 2016), indicating an enhancement 
of southeastward moisture transport. Our analysis of GPCP precipitation and surface salinity observations indicate strong precipitation and ocean freshening trends south of the subtropical highly-evaporative region, also suggesting an enhancement of southward moisture transport. Therefore, there are indications that this extra moisture from increasing evaporation in the North Atlantic subtropics could have fed enhanced precipitation in a range of moisture recipient regions, other than the subpolar North Atlantic.

\subsubsection{Salinity}

Figure 3 shows the 40-year (1979-2018) salinity mean and change zonally averaged in a latitudinal section across the Atlantic basin. The surface layers of the subtropical North and South Atlantic are the most saline open ocean regions on the globe (i.e. excluding marginal seas). This is due to a locally large excess of evaporation $(E)$ over precipitation $(P)$ and river runoff $(R)$. Lower surface salinities are encountered in the topical Atlantic due to relatively high rainfall and riverine inputs and in the Southern Ocean and sub-polar North Atlantic, which in addition receive high surface freshwater inputs from the polar regions. In most regions the spatial pattern of 3-D salinity change clearly shows an amplification of the salinity mean field with relatively saline regions becoming saltier and relatively fresh regions becoming fresher in accordance with an intensified water cycle.

Very strong salinification is observed in the upper layer of the two (South/North) Atlantic subtropical regions while
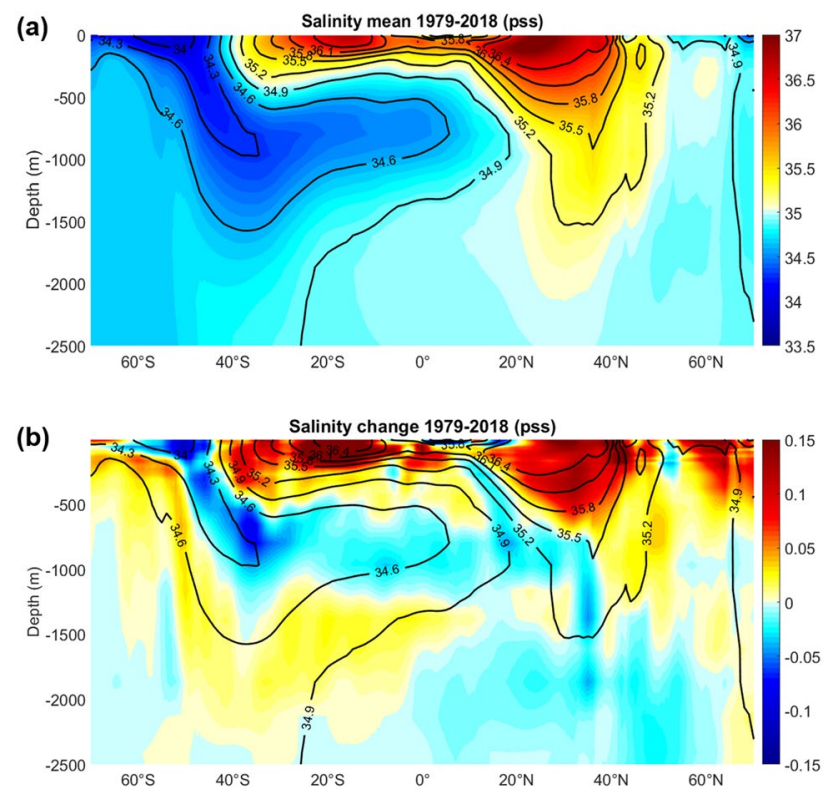

Fig. 3 Meridional vertical section of zonally mean salinity across the Atlantic Ocean from En4 dataset. a Climatological mean salinity. b Salinity change over 1979-2018. Climatological mean salinity contours every 0.3 pss are also depicted freshening is observed in the surface layer of the tropics and the Southern Ocean. Substantial salinification is also seen in the upper thermocline waters within the tropical/ subtropical Atlantic. A strong freshening signal between $500 \mathrm{~m}$ and $1200 \mathrm{~m}$ of the subtropical South Atlantic and tropical South/North Atlantic is coincident with subduction into the Southern Ocean thermocline, following the pathways of Subantarctic Mode Water (SAMW) and Antarctic Intermediate water (AAIW) along isopycnals at intermediate depths. The general sub-surface salinity change pattern over the last 40 years (1979-2018) obtained here is consistent with previous long-term salinity trend analyses spanning periods up to 2010 showing an increase of the salinity maximum of upper thermocline waters and a decrease of the salinity minimum of intermediate waters across the Atlantic (Helm et al. 2010; Durack and Wijffels 2010; Skliris et al. 2014). However, an exception to this amplified spatial pattern is the upper $(\sim 500 \mathrm{~m})$ layer of the North Atlantic subpolar region, where, apart from the central-eastern part of the basin which shows freshening, a long-term salinification is observed everywhere else.

In general, although inter-annual variability is strong, there are significant trends in the upper $500 \mathrm{~m}$ layer salinity in the two subtropical regions and the tropical region after the 1970's, whereas deep layer salinity change is small. The upper layer salinity long-term trend in the sub-polar region is predominantly driven by a strong and persistent salinity increase after the early 1990s (Fig. 4). This trend is however reversed after the late 2000 s with a strong freshening counterbalancing a large part of the salt content increase in the previous period (Holliday et al. 2015). Below $500 \mathrm{~m}$ depth, freshening persists in the North Atlantic sub-polar region until the early 2000 s.

In general, upper layer salinity in the North Atlantic subpolar region shows very strong decadal variability, often obscuring any long-term climatic trends (Stendardo et al. 2016; Reverdin et al. 2019). A large part of this decadal variability is often attributed to changes in Arctic freshwater inputs. A pronounced freshening trend was observed in the late 1960's and 1970's associated with the Great Salinity Anomaly (GSA) driven by anomalous high freshwater imports from the Arctic (Dickson et al. 1988). Similar Great Salinity Anomalies (GSAs), but of lesser magnitude, have also been observed propagating around the North Atlantic sub-polar gyre over recent decades (i.e. Belkin 2004; Wadley and Bigg 2006). In addition, the salinity spatial pattern is affected by changes in the intensity and pathways of relatively salty and fresh water transports associated with the (northward) North Atlantic Current (NAC) and (southward) Labrador Current $(L C)$, respectively.

Moreover, natural modes of variability may have a pronounced effect on the salinity pattern in the sub-polar region. Friedman et al. (2017) showed that subpolar sea 

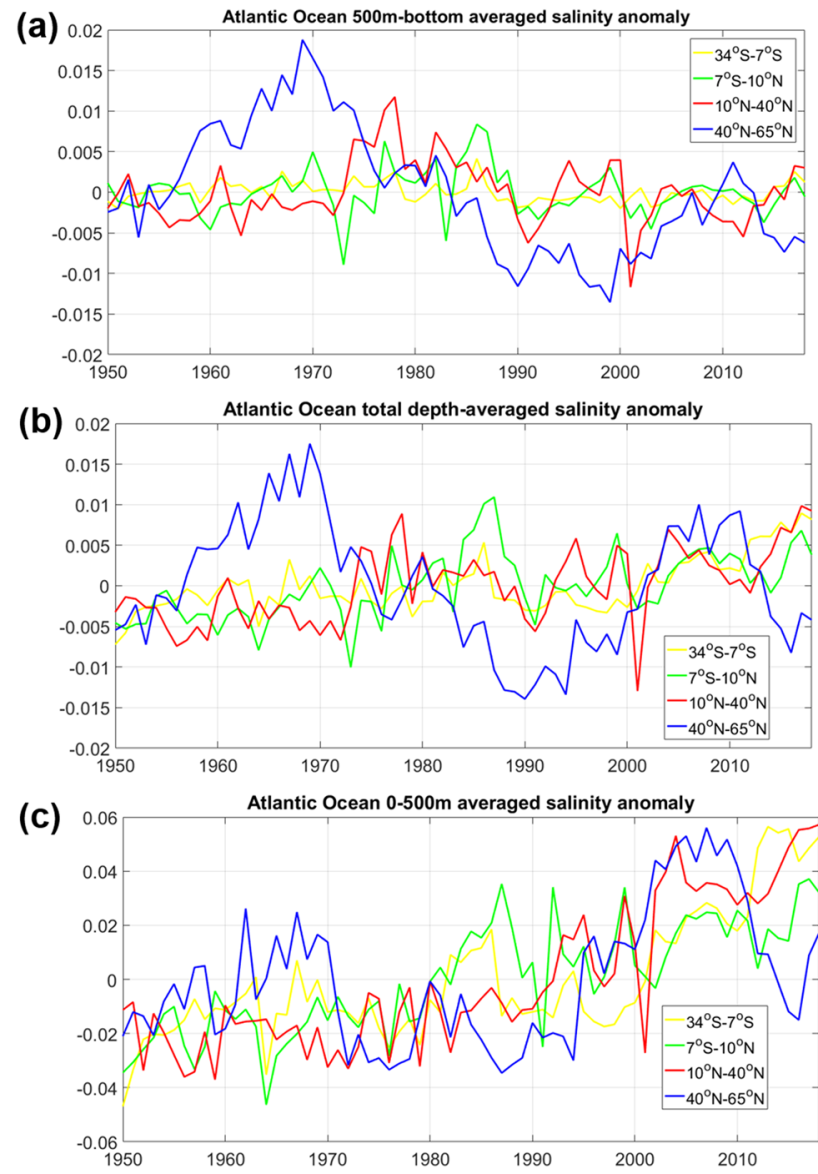

Fig. 4 Annual timeseries (1950-2018) of volume-averaged salinity for the total water column (a), upper $500 \mathrm{~m}$ layer (b), and $500 \mathrm{~m}$-bottom layer (c) over the South Atlantic subtropical $\left(34^{\circ} \mathrm{S}-7^{\circ} \mathrm{S}\right.$, yellow), tropical $\left(7^{\circ} \mathrm{S}-10^{\circ} \mathrm{N}\right.$, green), North Atlantic subtropical $\left(10^{\circ}\right.$ $\mathrm{N}-40^{\circ} \mathrm{N}$, red), and sub-polar $\left(40^{\circ} \mathrm{N}-65^{\circ} \mathrm{N}\right.$, blue) regions

surface salinity ( $S S S$ ) varies in phase with $A M O$. In particular, a positive (negative) phase of $A M O$, which is associated with a strengthening (weakening) of the $A M O C$, results in increased (decreased) salt transport from the sub-tropics to the sub-polar gyre (Zhang et al. 2007). Therefore, high salinity increases evidenced in most of the sub-polar region over 1979-2018 period may at least partially be explained by the strongly increasing (from negative to positive) $A M O$ index over this period. $N A O$ also exerts a strong impact on salinity decadal variability in the sub-polar region, by controlling the location of the subpolar front i.e. separating the sub-polar from the sub-tropical gyre, and the advection of salinity anomalies by NAC into the western sub-polar North Atlantic (Hakkinen and Rhines 2009; Stendardo et al. 2016).

The volume-averaged Atlantic salinity (i.e. integrated from $34^{\circ} \mathrm{S}$ to $65^{\circ} \mathrm{N}$ ), although clearly varying at multidecadal scales, significantly increases over the 1979-2018 period, in line with observed increasing net evaporation and large salinity gains in the upper $500 \mathrm{~m}$ layer found almost everywhere across the meridional sector (Fig. 5b). The general freshening obtained below the upper $500 \mathrm{~m}$ layer (Fig. 5c) is not sufficient to counterbalance the upper layer's substantial salinity gain.

\subsubsection{Linking long-term salinity and water cycle changes}

The spatial distribution of the mean SSS field strongly resembles that of the mean $E-P$ field since the latter is the main driver of its spatial variability. However, ocean advection and mixing strongly shape the surface salinity field at seasonal/interannual timescales (Yu 2011) so that there is generally a low link between $S S S$ and $E-P$ variability locally in large parts of the world's ocean at these timescales. On the other hand, one expects much higher consistency between large scale spatial patterns of change of the two parameters at multidecadal timescales. Indeed, the long-term water cycle change spatial pattern since the 1950s has been already imprinted in the global ocean salinity field (Durack et al. 2012; Skliris et al. 2016; Zika et al. 2018). The spatial patterns of change between SSS (Fig. 5a) and $E-P$ (see Fig. 1a) over 1979-2018 obtained here also show a quite high consistency. Well-coordinated broad-scale patterns of increased surface layer salinity and increased net evaporation are found in the two subtropical regions, whereas widespread freshening in the tropical region is consistent with increased net precipitation there. Also, the long-term decrease in net precipitation in a large part of the North Atlantic sub-polar region is consistent with salinity increases there. However, broad-scale patterns of change in $E-P$ are generally less spatially coherent than those in SSS. Only about $45 \%$ of grid points present statistically significant trends (at the $95 \%$ confidence interval) in $E-P$ as compared to $60 \%$ of grid points in SSS. Moreover, there are a few areas of opposing trends in $E-P$ and SSS, notably in the sub-polar region. As mentioned above, the spatiotemporal variability of salinity in the sub-polar gyre is also strongly controlled by decadal changes in Arctic freshwater inputs and prominent ocean circulation patterns, which in turn are strongly controlled by the major natural climate modes affecting the high-latitude North Atlantic, such as $N A O$ and $A M O$.

\subsection{4 $26.5^{\circ} \mathrm{N}-65^{\circ} \mathrm{N}$ anomalous freshwater budget over 1979-2018}

The $A M O C$ and $F W T$ have been continuously estimated at $26.5^{\circ} \mathrm{N}$ in the Atlantic since 2004 by the RAPID Climate Change measurement program (McDonagh et al. 2015; Smeed et al. 2018), but with the absence of long-term timeseries of hydrographic properties at other latitudes, the relative importance of changing $F W T$ divergence remains highly uncertain. Here, we investigate the anomalous freshwater 

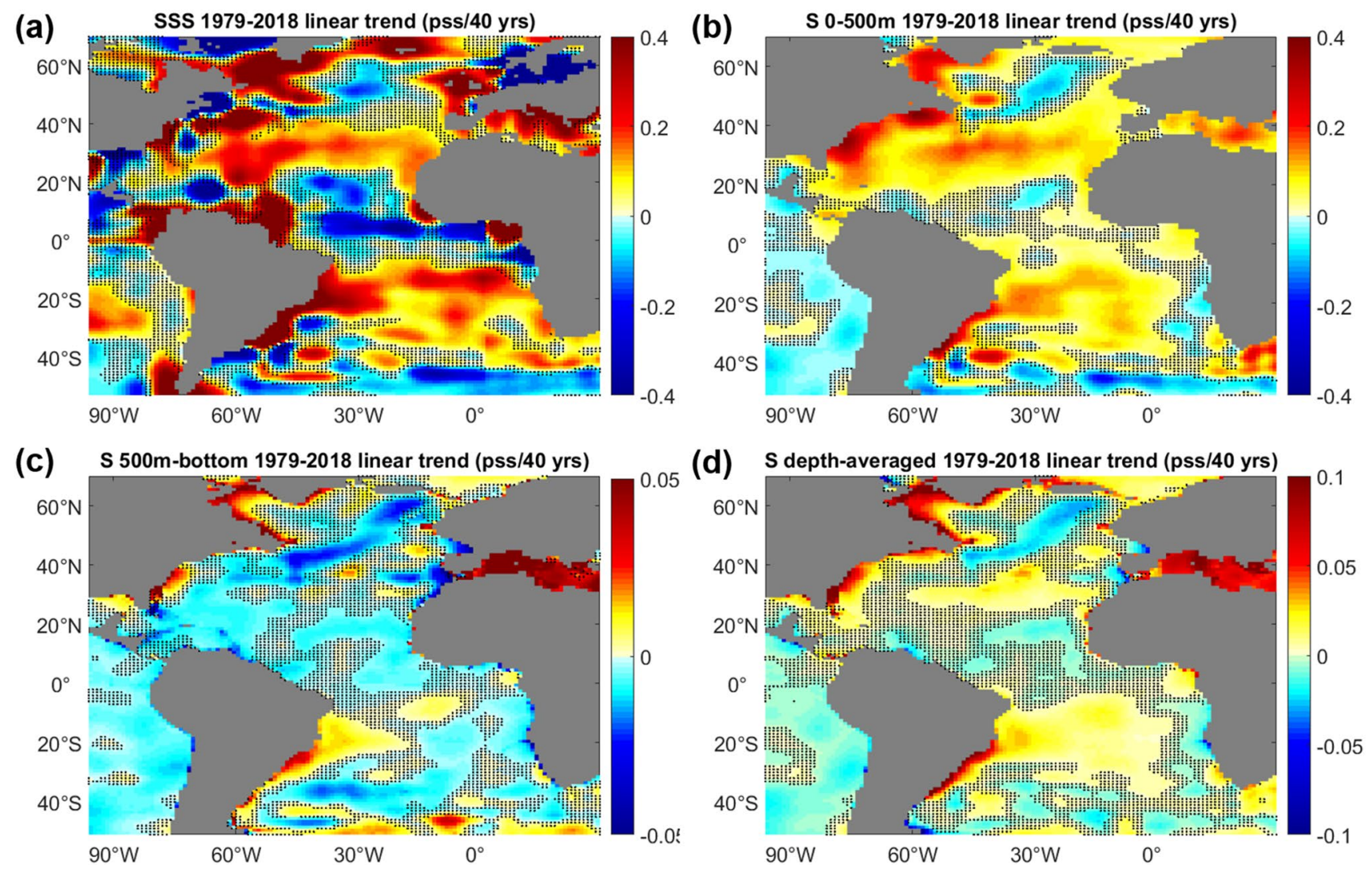

Fig. 5 Spatial patterns of salinity change in the Atlantic Ocean over 1979-2018 from the En4 dataset. a Sea surface salinity; b 0-500 m layer; c $500 \mathrm{~m}$-bottom layer; $\mathbf{d}$ total depth-average. Regions where the linear trend is not significant at the $95 \%$ confidence level are stippled

budget in the area bounded to the South by $26.5^{\circ} \mathrm{N}$ where changes in $A M O C$ and $F W T$ can be more reliably estimated, and the northern boundary of the Atlantic at $65^{\circ} \mathrm{N}$. Taking into account the $26.5^{\circ} \mathrm{N}-65^{\circ} \mathrm{N}$ area averaged $E-P$ change (from $O A F l u x / G P C P$ ), the equivalent 3-D freshwater content change (inferred from the total depth volume-averaged salinity change in En4) and the estimated $F W T$ change at $26.5^{\circ} \mathrm{N}$ from McDonagh et al. (2015), we may estimate $F W T$ change at the northern Atlantic boundary at $65^{\circ} \mathrm{N}$ needed to close the anomalous freshwater budget for this area over 1979-2018. In our calculations we ignore any change of freshwater transports at the Gibraltar Strait, as the mean net freshwater transport there is an order of magnitude less than the estimated change in $F W T$ at $26.5^{\circ} \mathrm{N}$.

Recent estimates based on RAPID array measurements demonstrate a decreasing $A M O C$ strength at $26.5^{\circ} \mathrm{N}$ over 2004-2016 (Smeed et al. 2018; Worthington et al. 2019). Over 2004-2013, estimates of $F W T$ at $26.5^{\circ} \mathrm{N}$ also show that southward FWT has decreased with the AMOC (McDonagh et al. 2015), although the time series reveals inter-annual variability of $\sim 0.2 \mathrm{~Sv}$. By comparing the recent timeseries at $26.5^{\circ} \mathrm{N}$ with hydrographic observations at $24.5^{\circ} \mathrm{N}$ in the mid-1970s, McDonagh et al. (2015) showed that southward $F W T$ has largely increased, by $\sim 0.34 \mathrm{~Sv}$. The area-averaged $\left(26.5^{\circ} \mathrm{N}-65^{\circ} \mathrm{N}\right)$ annual timeseries over the last 40 years show that net air-sea freshwater flux has trended positive (more net evaporation). Volume-averaged salinity strongly varied at multi-decadal scales, with strong salinity gains after the early 1990's (Fig. 4).

Surface freshwater flux change over 1979-2018 amounts to $\sim 0.12 \pm 0.03 \mathrm{~Sv}$ increased export of freshwater over the whole area. Adding the (southward) $F W T$ increase of $\sim 0.34 \pm 0.20 \mathrm{~Sv}$ at $26.5^{\circ} \mathrm{N}$ we obtain an increase of the total freshwater export of $0.46 \pm 0.21 \mathrm{~Sv}$ while the freshwater content (based on volume-averaged salinity change) decreased by only $0.02 \pm 0.01 \mathrm{~Sv}$. In order to close the anomalous freshwater budget for this area a (southward) $F W T$ increase at the northern Atlantic boundary at $65^{\circ} \mathrm{N}$ of $0.44 \pm 0.21 \mathrm{~Sv}$ is therefore needed. In the last 3 decades, the Arctic Ocean shows a large freshening trend (Haine et al. 2015; Carmack et al. 2016) associated with higher river freshwater inputs (Dai et al. 2009) and especially increasing rates of Greenland Ice Sheet mass loss (Forsberg et al. 2017). However, despite this dramatic change in the Arctic freshwater budget, recent studies show that the Arctic freshwater inputs into the Atlantic do not present significant changes over the last few decades (Haine et al. 2015; Carmack et al. 2016). On the contrary, strongly increasing 
salinities at high latitude North Atlantic, as evidenced in the En4 dataset used here, could at least partially explain such a drastic increase in southward freshwater transport (northward salt transport). "Atlantification" has been underway in the Barents Sea since around 2000, whereby a cold stratified regime is transitioning to a warm mixed regime; Atlantic Water mixes with overlying Arctic Water, most vigorously in a "frontier region" (Lind et al. 2018), which is migrating into the Arctic. Near-surface salinity has risen from $\sim 33 \mathrm{psu}$ averaged over 1970-99 to 34 psu by $2010-16$ (Fig. $2 \mathrm{~h}$ in Lind et al. 2018). The equivalent trend in freshwater content in the upper $100 \mathrm{~m}$ is estimated at just over $-1 \mathrm{~m} / \mathrm{m}^{2}$, over 2000-16 (Fig. 3b in Lind et al.). Taking an approximate area of the Barents Sea as $1.4 \times 10^{6} \mathrm{~km}^{2}$, this change amounts to $\sim-0.003 \mathrm{~Sv}$, which is 2 orders of magnitude lower than our inferred FWT change $(\sim 0.44 \mathrm{~Sv})$. If similar salinity gain (and implied freshwater loss) throughout the water column is supposed, taking mean depth of $600 \mathrm{~m}$ we obtain an associated freshwater export, from just the Barents Sea, of $\sim-0.018 \mathrm{~Sv}$ - still rather small compared to our inferred FWT change at $65^{\circ} \mathrm{N}$, demanding considerable additional (an order of magnitude more) salinity gain throughout the Nordic Seas and the wider Arctic. While the Barents Sea is relatively shallow, it may be that salinity changes in the deep Nordic Seas and Arctic can account for this salinity gain; recent warming associated with Atlantic Water across the Nordic Seas (Lauvset et al. 2018) and the Arctic (Polyakov et al. 2012) is consistent with this. However, again, an absence of long-term measurements of volume/salt transports through the main straits of the Arctic/Atlantic boundary do not allow us to corroborate this hypothesis.

Assessing an observationally-based anomalous freshwater budget of the Atlantic at multi-decadal scales is not only strongly constrained by large uncertainties in the estimation of changes in FWT divergence, but also by uncertainties in estimating 3-D salinity and surface freshwater flux changes. In general, although better constrained by observations over the satellite era there are still limitations and large discrepancies among atmospheric re-analysis/satellite-derived products in representing long-term variability and trends in $E$ and $P$ over the ocean (e.g. Schanze et al. 2010; Skliris et al. 2014). There are also large uncertainties in estimating salinity trends in the deeper layers, especially below the ARGO float typical deployment depth of $2000 \mathrm{~m}$ (Skliris et al. 2014). Importantly, the 40-year time series considered here are relatively short in duration for adequately averaging out multi-decadal fluctuations due to natural variability to properly capture long-term climatic trends (e.g. Sohn et al. 2013). Consequently, large-scale multi-decadal natural variability signals such as those associated with $N A O$ and $A M O$ are imprinted in the $E-P$ and salinity spatial patterns of change over this relatively short period (Friedman et al. 2017). Stendardo et al. (2016) used a high-resolution 20-year salinity timeseries (1993-2012) of the upper layer of the mid-high latitude North Atlantic to show that strong multiyear variability obscured any long-term climatic trends in most of the sub-polar region.

\subsection{CMIP5 simulations}

Given the large uncertainty in estimating observed changes in all components of the Atlantic Ocean freshwater budget as described above, the CMIP5 simulations permit the investigation of long-term changes and the assessment of the various highly inter-linked mechanisms and ocean/atmosphere feedbacks controlling the Atlantic freshwater budget, especially in the context of a warming-driven amplification of the water cycle.

Variations of the global water cycle amplitude show large statistically significant (at the $99 \%$ confidence interval) positive linear trends over the 21 st century in all 10 CMIP5 models and in both RCP scenarios considered here (see Fig. 3 in Skliris et al. 2016). At the end of the 21st century, the amplification of atmospheric branch of the global water cycle (with respect to a pre-industrial state) in our CMIP5 ensemble mean is estimated to be $\sim 7 \%$ in the intermediate green-house gas mitigation scenario RCP 4.5 , and $~ 18 \%$ in the continued high greenhouse-gas emission scenario RCP8.5 (Skliris et al. 2016).

\subsubsection{Surface freshwater fluxes}

Figure 6 shows the meridional distribution of zonally-integrated net surface freshwater flux $(P-E+R)$ across the Atlantic, averaged over the last 40 years of the historical (1966-2005) and RCP4.5/RCP8.5 (2061-2100) simulations. The historical multi-model mean distribution is close to the observed distribution, although there is an overestimation of the water cycle amplitude in the subtropical regions. Results indicate increased net precipitation in the sub-polar region and increased net evaporation in the South and North Atlantic subtropical regions across all latitudes in both RCP scenarios as expected by a warming-driven amplification of the water cycle. However, on the other hand, there is an overall small reduction in net precipitation in the tropical region with opposing trends of decreasing net precipitation in the northern part $\left(\sim 3^{\circ} \mathrm{N}-10^{\circ} \mathrm{N}\right)$ and increasing net precipitation in the southern part $\left(\sim 7^{\circ} \mathrm{S}-3^{\circ} \mathrm{N}\right)$. The obtained surface freshwater flux change dipole pattern in the tropical region reflects a southward shift of ITCZ that is more pronounced in the higher warming RCP8.5 scenario. In general, most CMIP5 models predict a narrowing and weakening of the ITCZ with warming over the 21st century (Byrne et al. 2018).

Integrating $P-E+R$ change over the whole Atlantic Ocean area (Fig. 6c) we obtain an increase in net evaporation 

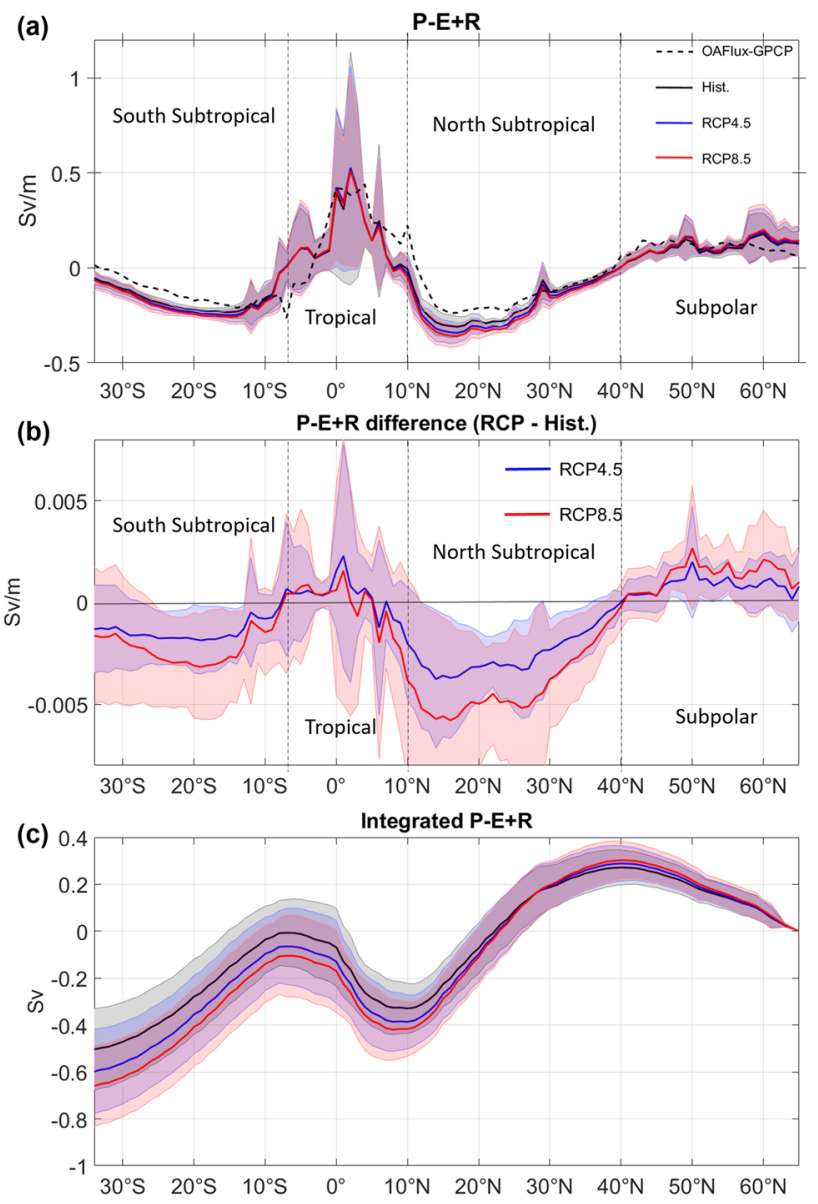

Fig. 6 a Meridional distribution of zonally integrated net surface freshwater flux $(P-E+R)$, normalized to $S v$ per meter in latitude $(\mathrm{S} v / \mathrm{m})$, from observations (dashed black), and CMIP5 multi-model mean historical (solid black), RCP4.5 (blue), and RCP8.5 (red) simulations (averaged over the last 40 years of each experiment). b Difference between meridional distribution of zonally integrated $P-E+R$ between RCP4.5/RCP8.5 and historical multi-model means. $\mathbf{c}$ Meridional distribution of accumulated $P-E+R$ from $65^{\circ} \mathrm{N}$ to $34^{\circ} \mathrm{S}$ for historical, RCP4.5 and RCP8.5 multi-model means. Solid lines depict ensemble means and shaded areas depict one standard deviation limits

from $\sim 0.48 \pm 0.13 \mathrm{~Sv}$ in the historical multi-model mean to $\sim 0.60 \pm 0.18 \mathrm{~Sv}$ in RCP4.5 and $\sim 0.67 \pm 0.16 \mathrm{~Sv}$ in RCP8.5 (averages over the last 40 years of each experiment) indicating substantial increases of $\sim 25 \%$ and $\sim 40 \%$, respectively.

Figure 7 shows annual timeseries of area-integrated $E-P-R$ for the four sub-regions. With the exception of the tropical region where long-term trends are very small and not statistically significant (at the $95 \%$ confidence inter$\mathrm{val}$ ), significant positive linear trends in net evaporation are obtained in the two (South/North) subtropical regions and in net precipitation in the sub-polar region. In all three regions steady increases in net (positive/negative) surface freshwater flux throughout the 21 st century are observed in RCP8.5, whereas in RCP4.5 there is a stabilization after around mid-century. The largest water cycle amplitude increase is obtained in the North Atlantic subtropical region (RCP4.5: $10.6 \pm 8.6 \%$; RCP8.5: $19.4 \pm 10.4 \%$ ) followed by the South Atlantic subtropical region (RCP4.5: $8.9 \pm 5.1 \%$; RCP8.5: $14.3 \pm 12.1 \%)$ and the sub-polar region (RCP4.5: $6.1 \pm 5.1 \%$; RCP8.5: $11.7 \pm 8.9 \%)$.

Small positive linear trends are also evidenced after the mid-1970's in the historical ensemble mean in the two subtropical regions. However trends and especially inter-annual/ decadal variability are much lower in historical simulations as compared to observations. In particular the observed strong decadal decrease in net precipitation in the sub-polar region is not reproduced in the CMIP5 ensemble whereas decadal trends in future projections remain smaller than the observed one even for the RCP8.5 scenario.

\subsubsection{Ocean freshwater transports}

Figure 8 shows the meridional distribution of the zonalaveraged CMIP5 multi-model mean $F W T$ across the Atlantic for historical, RCP4.5, and RCP8.5 experiments (temporal means over the last 40 years for each experiment). Freshwater is transported southwards $(F W T<0)$ in most of the Atlantic sector. From the Arctic boundary, FWT magnitude increases to a maximum in the subtropics and declines southwards. CMIP5 projections for both RCP4.5 and RCP8.5 scenarios clearly show that over the longer timescale, strong trends in $F W T$ emerge following the water cycle amplification. $F W T$ trends towards more negative values (i.e. $F W T$ strengthens southwards) throughout the Atlantic Ocean over the 21 st century, with these changes being more pronounced in the higher warming RCP8.5 scenario. The meridional mean increase in the multi-model mean (southward) $F W T$ (with respect to historical mean) is $\sim 0.042 \pm 0.014 \mathrm{~Sv}$ and $\sim 0.055 \pm 0.022 \mathrm{~Sv}$ in RCP 4.5 and RCP8.5, respectively. FWT change is much larger in the North Atlantic sub-tropical and sub-polar regions with $F W T$ increase reaching on average $15 \%$ and $20 \%$, in RCP4.5 and RCP8.5, respectively.

Results indicate a substantial reduction in $A M O C$ strength across the Atlantic (Fig. 8b). The meridional mean reduction in the multi-model mean (with respect to historical mean) is $\sim 19 \pm 4 \%$ and $~ 33 \pm 6 \%$ in RCP 4.5 and RCP 8.5 , respectively, in agreement with probabilistic assessments of $A M O C$ projections based on CMIP5 (e.g. Schleussner et al. 2014). The largest reduction in AMOC strength is obtained near the boundary of North Atlantic subtropical and subpolar regions reaching $40 \%$ in RCP8.5. A consequence of the $A M O C$ decline is a southward shift of the ITCZ. This may be explained by an equatorward shift of the latitude of maximum heating causing the dividing latitude of the northern and southern hemisphere Hadley circulation cells to shift southward (Drijfhout 2010; Mecking et al. 2016). 
(a)

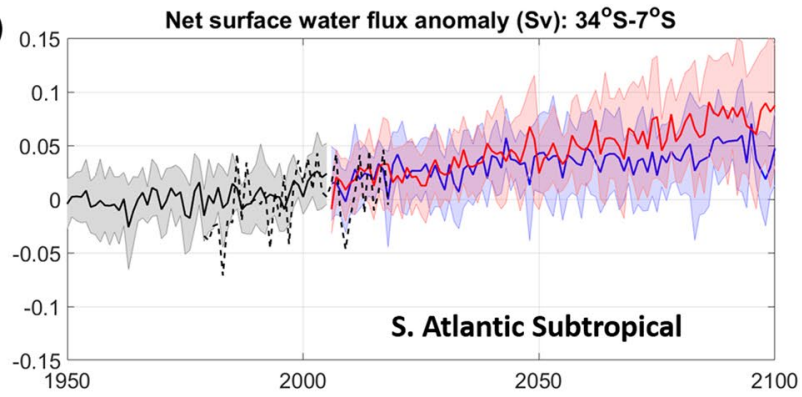

(c)

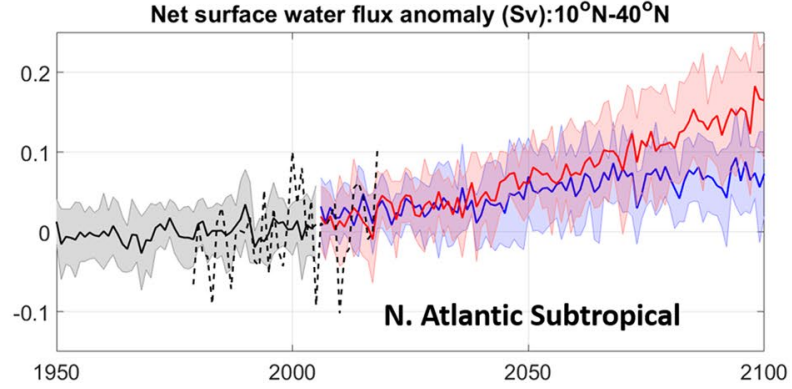

Fig. 7 Annual timeseries of multi-model mean area-averaged $E-P-R$ in Sv over 1950-2100 in the four sub-regions of the Atlantic for historical (black), RCP4.5 (blue), and RCP8.5 (red) simulations. a S. Atlantic Subtropical, b Tropical Atlantic, c N. Atlantic (b)

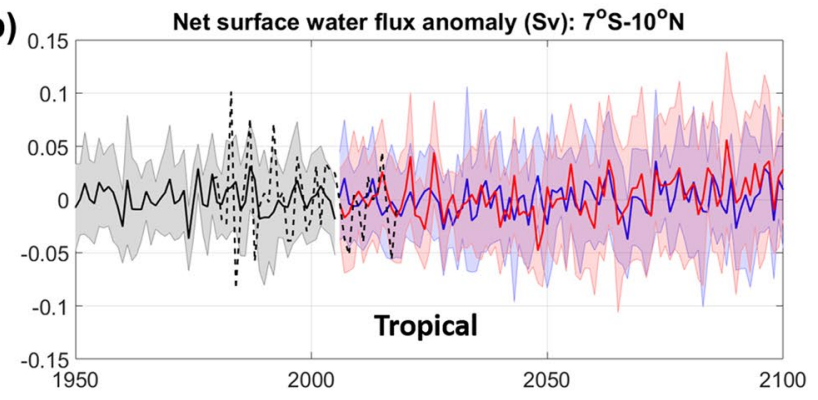

(d)

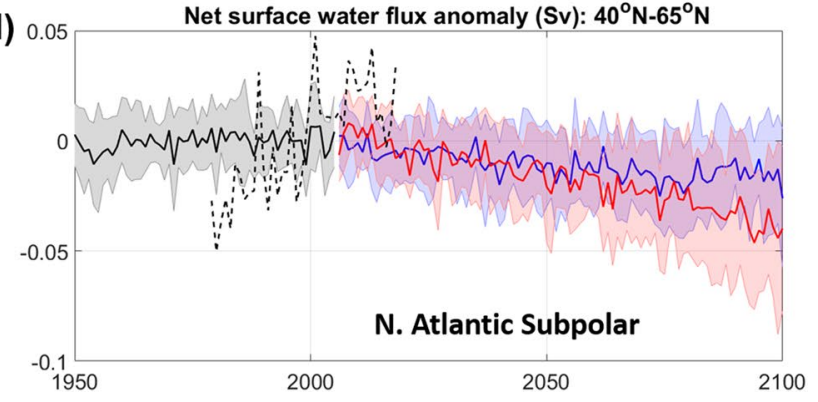

Subtropical, d N. Atlantic Subpolar. Solid lines depict ensemble means and shaded areas depict one standard deviation limits. Observationally-based annual area-averaged $E-P$ data $(O A F l u x-G P C P)$ over 1979-2018 (dashed black) is also depicted

(b)

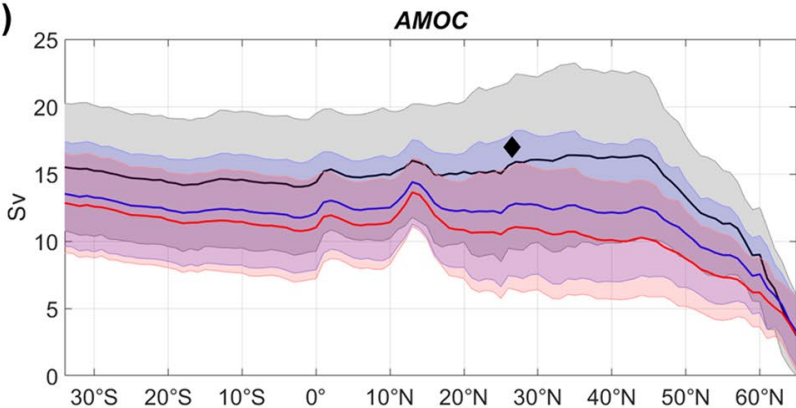

(d)

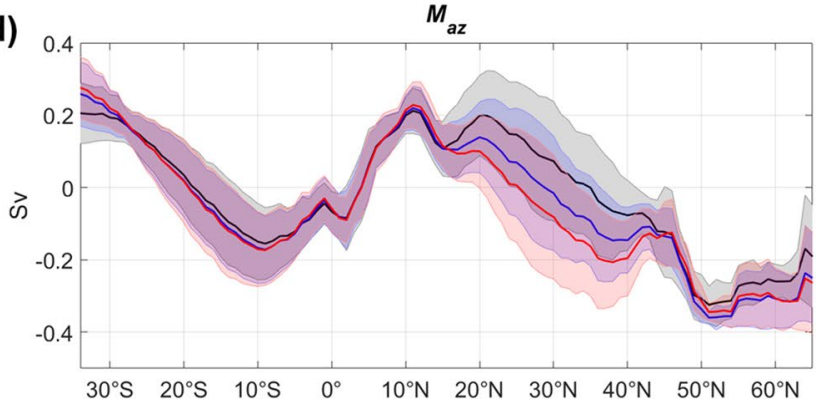

and $\mathbf{d} M_{a z}$. Black diamond depicts observational estimates at $26.5^{\circ}$ $\mathrm{N}$ (McDonagh et al. 2015). Solid lines depict ensemble means and shaded areas depict one standard deviation limits

The ensemble-mean historical mean meridional distribution of $M_{o v}$ (Fig. 8c) shows that it is negative in most of the Atlantic Ocean transporting freshwater southwards/salt 
northwards. $M_{o v}$ magnitude strongly decreases in RCP4.5/8.5 in the sub-tropical North Atlantic (i.e. becomes less negative), following the large reduction in $A M O C$ strength, but increases (becomes more negative) in the tropical and subpolar regions. In order to assess the drivers of $M_{o v}$ variability, we also calculated temporal variations in $M_{o v}$ by considering meridional current velocity variations $\left(V^{\prime}\right)$ but keeping salinity fixed at the long-term average value $(\bar{S}), M_{o v}\left(V^{\prime}, \bar{S}\right)$, and considering salinity variations but keeping meridional velocity fixed, $M_{o v}\left(S^{\prime}, \bar{V}\right)$; see Appendix Fig. S1. The two terms have clearly opposing contributions to $M_{o v}$ change throughout the Atlantic. Salinity variations counterbalance part of the effect of decreasing $A M O C$ on $M_{o v}$ in the North Atlantic sub-tropical region, whereas they have a greater impact than decreasing $A M O C$ on $M_{O v}$ in the tropical and sub-polar regions.

Ensemble-mean $M_{a z}$ is positive through most of the subtropical Atlantic regions, transporting freshwater northwards/salt southwards and opposing $M_{o v}$ transport there, whereas it is negative (southward) everywhere else (Fig. 8d). $M_{a z}$ strongly decreases in RCP4.5/8.5 from positive to negative values in the sub-tropical North Atlantic, resulting in strongly increasing southward freshwater transport that largely exceeds the opposing trend of decreasing $F W T$ due to $M_{o v}$ reduction. On the contrary, both $M_{o v}$ and $M_{a z}$ changes contribute to increasing southward $F W T$ in the sub-polar North Atlantic. It is interesting to note that $M_{a z}$ contribution to $F W T$ change in both RCP scenarios is very small in the tropical and South Atlantic subtropical regions

(a)

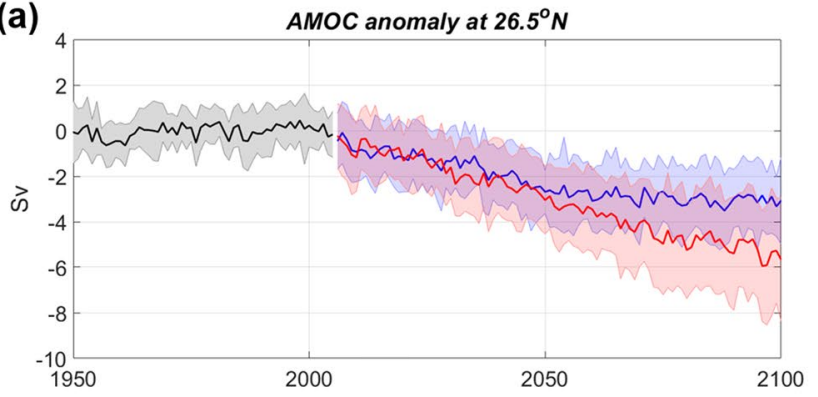

(c)

$M_{\text {ov }}$ anomaly at $26.5^{\circ} \mathrm{N}$

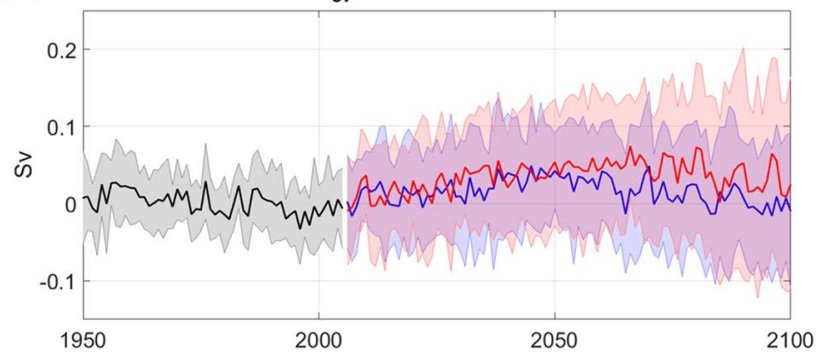

Fig. 9 Annual timeseries of multi-model mean anomalies of $A M O C$ (a), $F W T$ (b), $M_{o v}(\mathbf{c})$, and $M_{a z}(\mathbf{d})$ over $1950-2100$ at $26.5^{\circ} \mathrm{N}$ in the Atlantic for historical (black), RCP4.5 (blue), and RCP8.5 (red) simu- with the exception of the area near the southern boundary where $M_{a z}$ significantly increases, opposing $M_{o v}$ decrease there. Similarly to $M_{o v}$ we also calculated the terms $M_{a z}\left(V^{\prime}\right.$, $\bar{S})$ and $M_{a z}\left(S^{\prime}, \bar{V}\right)$ (Fig. S1) to assess relative contributions of salinity and meridional current variations to $M_{a z}$ change. As expected, salinity controls by far the changes in $M_{a z}$, especially in the North Atlantic sub-tropics, where the impact of $M_{a z}$ on freshwater transport is more pronounced.

To summarise, southward $F W T$ strongly increases in the subtropical North Atlantic in both RCP scenarios in spite of declining $A M O C$ (i.e. reduced southward $M_{o v}$ ), as the longterm $F W T$ trend is dominated by salinity change (reduced northward $M_{a z}$ ). In the sub-polar North Atlantic and subtropical South Atlantic, both decreasing $M_{a z}$ and $M_{o v}$ contribute to increasing southward FWT. Largest $F W T$ trends occur in areas of strong salinity change, such as the subtropical regions.

Figure 9 shows multi-model mean time variations of $A M O C, F W T$ and its two components $M_{o v}$ and $M_{a z}$ at $26.5^{\circ}$ $\mathrm{N}$ over the historical and RCP4.5/8.5 21 st century simulations. Our multi-model $A M O C$ mean strength at $26.5^{\circ}$ $\mathrm{N}$ over the last 40 years of the historical simulation is 15.6 \pm 5.9 Sv (multi-model mean $\pm 1 \mathrm{std}$ ), which is consistent with the observational mean estimate at the RAPID array of $17.0 \pm 1.9 \mathrm{~Sv}$ (mean \pm 1 std of annual-mean time series over 2004-2016, Smeed et al. 2018). $M_{o v}$ is $-0.49 \pm 0.13 \mathrm{~Sv}$ at $26.5^{\circ} \mathrm{N}$ in the historical multi-model mean, with its magnitude being substantially lower as compared to the observational estimate of $-0.78 \pm 0.21 \mathrm{~Sv}$ over $2004-2013$ (b)

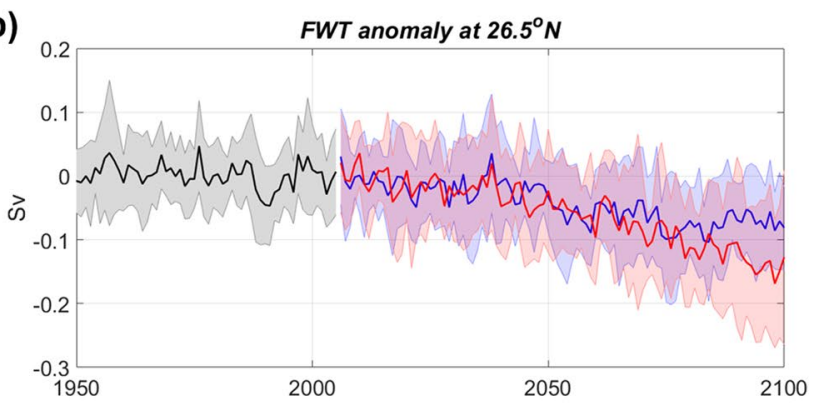

(d)

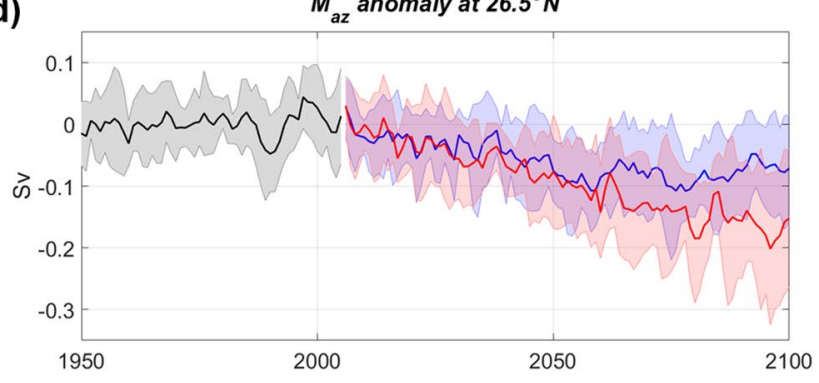

lations. Solid lines depict ensemble means and shaded areas depict one standard deviation limits 
(McDonagh et al. 2015). This discrepancy is probably due to velocity biases related to unresolved scales which do not allow the presence of eddies in the coarse resolution CMIP5 models (Mecking et al. 2016). FWT is $-0.36 \pm 0.07 \mathrm{~Sv}$ at $26.5^{\circ} \mathrm{N}$ in the historical multi-model mean, which is very close to the observational estimate of $-0.37 \pm 0.20 \mathrm{~Sv}$ over 2004-2013 (McDonagh et al. 2015).

Curiously, the $A M O C$ at $26.5^{\circ} \mathrm{N}$ slightly increases (although this is statistically significant only at the $90 \%$ confidence interval) after the 1970's in the historical multimodel mean which results in a negative (southward) tendency in $M_{o v}$. $A M O C$ strength at $26.5^{\circ} \mathrm{N}$ steadily decreases at a high rate in RCP8.5 reaching a $~ 35 \%$ reduction at the end of the 21 st century, whereas in RCP4.5 AMOC strength strongly decreases until approximately mid-century and stabilises after that. It is interesting to note that, following $A M O C$ variations, $M_{o v}$ becomes less negative (i.e. southward freshwater transport decreases) until mid-century in both RCP scenarios but then slightly decreases (i.e. southward freshwater transport increases) even in RCP8.5 where AMOC strength continues to decrease (although at a lower rate) until the end of the century. This suggests that salinity change becomes a predominant factor in $M_{o v}$ change at that latitude after roughly the 2050's. On the other hand, $M_{a z}$ steadily decreases from positive (northward) to negative (southward) values until the end of the century in RCP8.5 whereas it stabilises at $\sim$ mid-century in RCP4.5.

Our results clearly show that salinity-driven $M_{a z}$ variations mainly control $F W T$ change in the North Atlantic subtropical region over the 21st century. Multi-model mean (southward) $F W T$ magnitude at $26.5^{\circ} \mathrm{N}$ increases over the 21 st century from $0.37 \pm 0.07 \mathrm{~Sv}$ to $0.44 \pm 0.08 \mathrm{~Sv}$ in RCP4.5 and to $0.51 \pm 0.10 \mathrm{~Sv}$ in RCP8.5. Although these values represent substantial increases of $~ 19 \%$ and $~ 38 \%$ with respect to the historical mean $F W T$, they are much lower as compared to the observational estimate of McDonagh et al. (2015) of 0.34 Sv increase over a shorter period in the historical record (i.e. between mid-1970s and 2000s). Compared to CMIP5 models, observations at the RAPID array indicate a much larger interannual/decadal variability of AMOC strength over 2004-2016, with a range of variation of 7.3 Sv and very large reduction of $A M O C$ strength between periods 2004-2008 and 2008-2012 of $2.9 \mathrm{~Sv}$ (Smeed et al. 2018).

\subsubsection{Salinity}

Our CMIP5 ensemble-mean time-series for the regional volume average salinities show that except from the subpolar region, salinity gradually increases across the Atlantic over the 21 st century at roughly the same rate for both RCP scenarios until mid-century (Fig. 10). Then salinity increase is slowing down in RCP4.5, whilst it accelerates in RCP8.5. Volume-averaged salinity anomalies are about 30-40\% higher in RCP8.5 (as compared to RCP4.5) at the end of the 21 st century. The largest volume-average salinity increase in RCP8.5 is obtained in the North Atlantic subtropical region $(\sim 0.075 \pm 0.025)$ followed by the tropical (a)

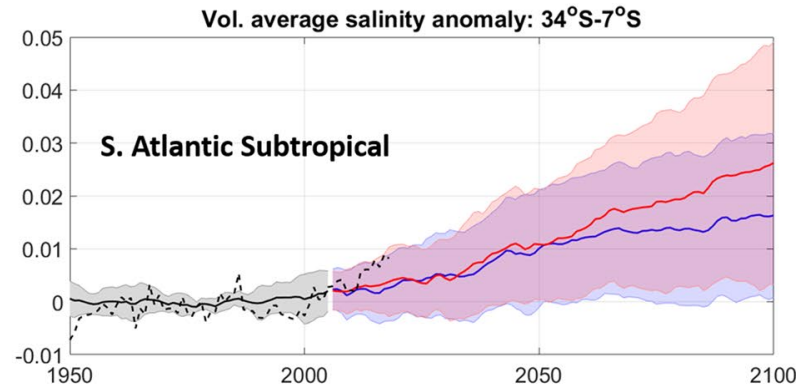

(c)

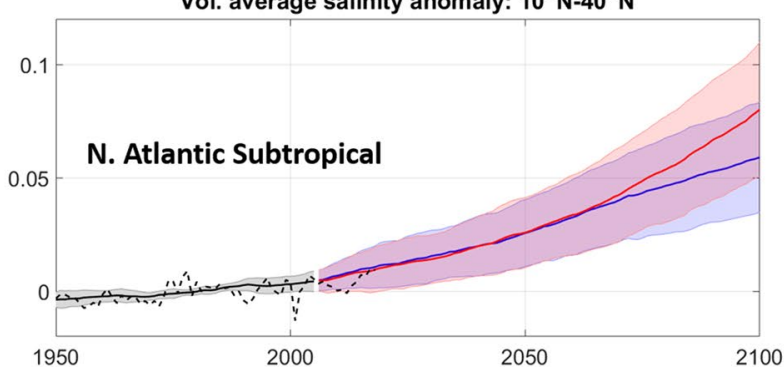

Fig. 10 Annual timeseries of multi-model mean volume-averaged salinity anomaly over 1950-2100 in the four sub-regions of the Atlantic for historical (black), RCP4.5 (blue), and RCP8.5 (red) simulations. a S. Atlantic Subtropical, b Tropical Atlantic, c N. Atlan- (b)

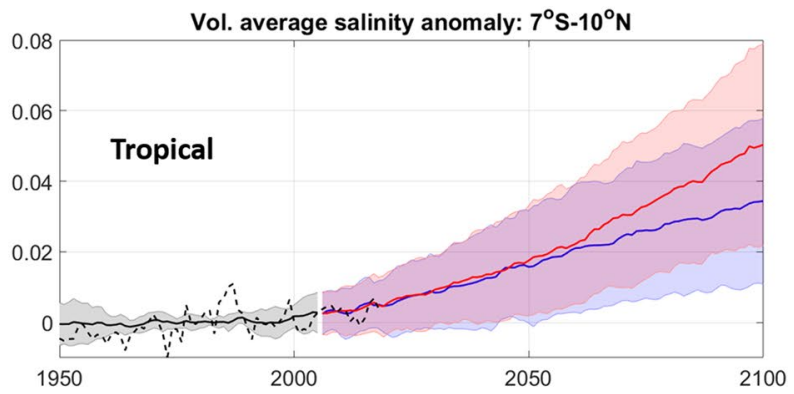

(d)

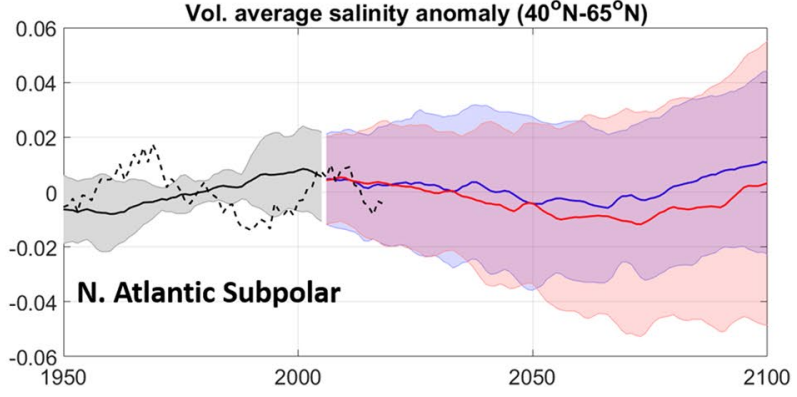

tic Subtropical, d N. Atlantic Subpolar. Solid lines depict ensemble means and shaded areas depict one standard deviation limits. Observationally-based annual area-averaged salinity (En4) over 1950-2018 (dashed black) is also depicted 
region $(\sim 0.050 \pm 0.030)$ while the South Atlantic sub-tropical region shows a much lower increase $(\sim 0.026 \pm 0.023)$. Salinity in the North Atlantic subtropical region starts to significantly increase after the early 1970's, which is in line with the observed pronounced salinity increase obtained here over 1979-2018. These findings are in accordance with previous studies demonstrating that the recent observed recent salinity increases in the sub-tropical North Atlantic significantly exceed internal natural variability in climate model control simulations (Stott et al. 2008; Terray et al. 2012), suggesting that the emerging trend is a part of anthropogenic climate change.

The CMIP5 ensemble mean shows increasing salinities in the sub-polar region over the historical period comparable to the strong salinity increase obtained in the observations over 1990-2010 (Fig. 10d). However as for the surface water flux the CMIP5 simulations do not capture the strong interannual and decadal variability in salinity evidenced in the observations. The sub-polar region shows a quite different salinity evolution over the 21 st century. The CMIP5 ensemble mean indicates a reduction in volume-averaged salinity until about the mid-2060s in both RCP scenarios following the net precipitation increase in the sub-polar region but then salinity increases again to roughly reach historical levels at the end of the century. Basin salt content evolution does not follow that of surface freshwater flux in the latter period suggesting that salt transport divergence mainly controls salinity variations. The strong salinification of the subtropical North Atlantic eventually leads to more saline waters being transported to the subpolar North Atlantic.

\subsubsection{Anomalous freshwater budget}

Figure 11 shows the anomalous freshwater budget for the four sub-regions of the Atlantic in RCP4.5 and RCP8.5, defined here as the difference between the last 40-year averages of historical (1966-2005) and RCP (2061-2100) simulations. The anomalous freshwater budget reveals the increasing magnitude of surface freshwater fluxes (except from the tropics) and southward freshwater transports across the Atlantic in both RCP scenarios, but with much larger anomalies (>50\%) being obtained in RCP8.5. Changes in

(a)

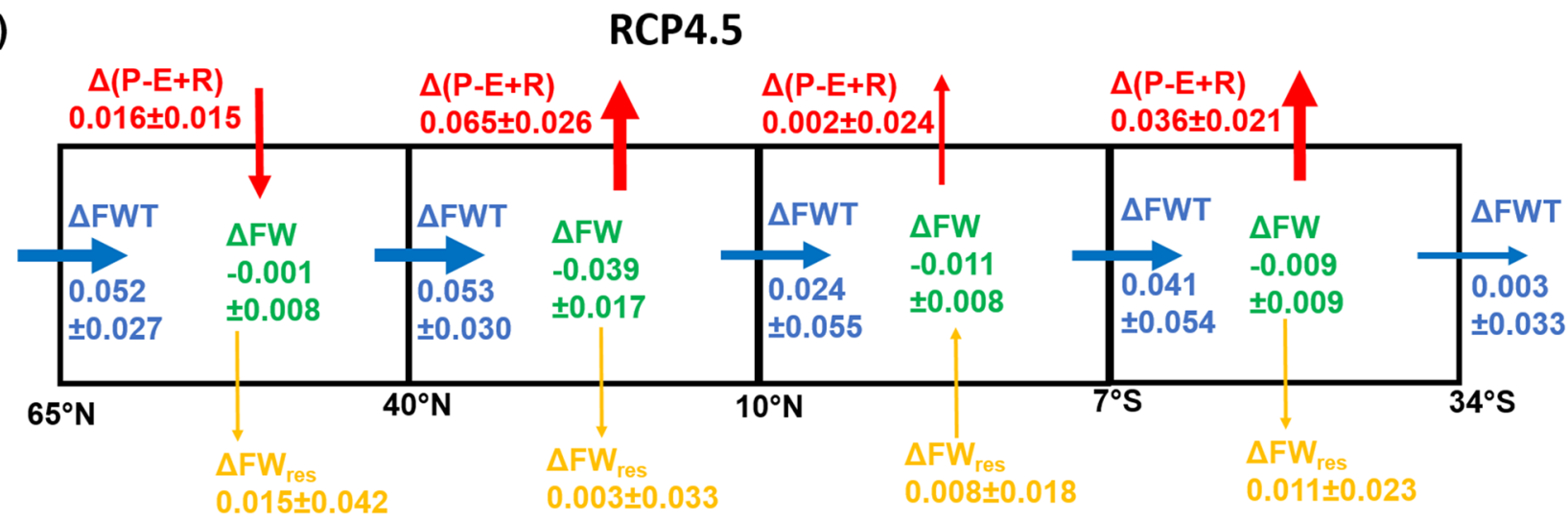

(b)

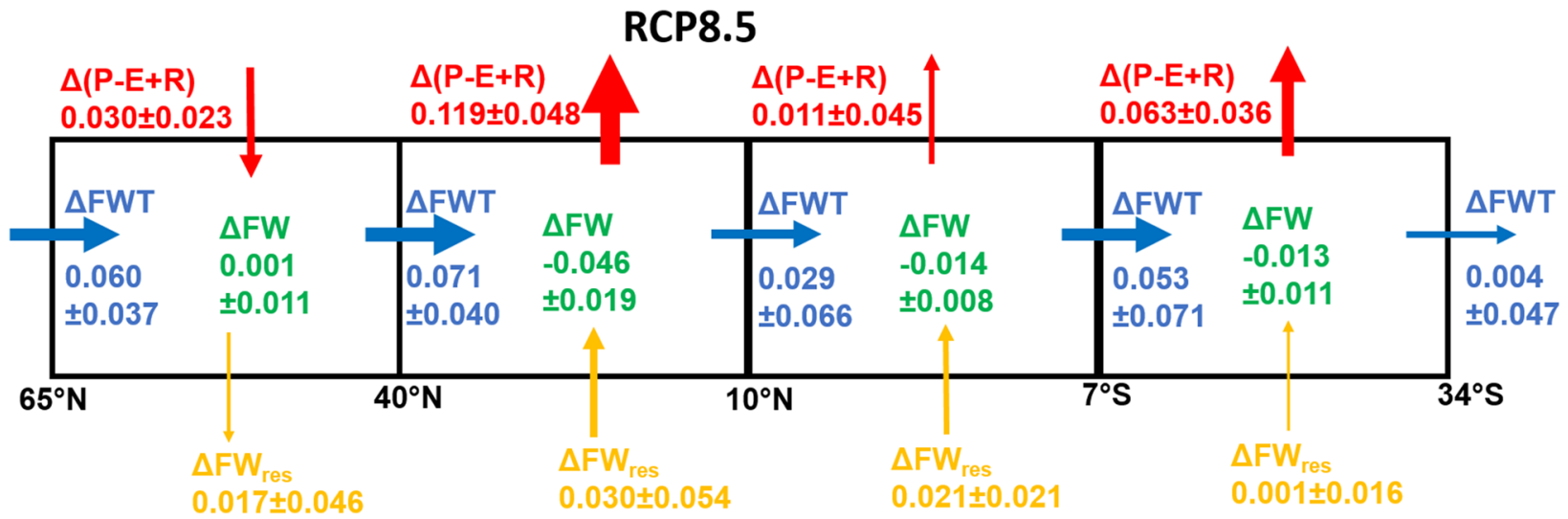

Fig. 11 Atlantic Ocean anomalous freshwater budget in RCP4.5 (a) and RCP8.5 (b) with respect to historical simulations. Anomalous freshwater fluxes and freshwater content (in Sv) are defined as the difference between the 40-year averages of historical (1966-2005) and RCP (2061-2100) simulations 
FWT meridional distribution in the RCP scenarios are consistent with an intensifying water cycle. Increasing $F W T$ convergence (i.e. increasing freshwater content) in the North/South Atlantic subtropical regions counterbalances increasing net evaporation (i.e. increasing export of freshwater), and increasing $F W T$ divergence in the subpolar region counterbalances increasing net precipitation.

In opposition to the "fresh get fresher paradigm", in the tropical region there is however a concomitant small reduction in net surface freshwater flux to the ocean, linked to the $A M O C$ decline, and a large increase in $F W T$ divergence, leading to a large reduction in freshwater content. In the North Atlantic subtropical region, increases in FWT convergence and mixing are not sufficient to balance the strong net evaporation increase leading to a significant decrease in freshwater content (increase in salt content) over the $21 \mathrm{st}$ century. On the contrary, in the sub-polar region the net precipitation increase is almost balanced by changes in mixing and $F W T$ divergence in both RCP scenarios. Residual terms in the anomalous freshwater budget are generally quite small compared to $F W T$ anomalies at the boundaries of each subregion, with the exception of the North Atlantic subtropical and the tropical regions in the RCP8.5 scenario. The large residual term denoting an anomalous freshwater input in the North Atlantic subtropical region could be explained by pronounced freshwater mixing at the boundaries as the salinity contrast with the adjacent relatively fresh regions strongly increases over the 21st century. Freshwater transport changes at the Gibraltar Strait are much smaller than the residual terms in the CMIP5 models considered here and in general have the opposite effect i.e. result in decreasing freshwater (increasing salt) inputs into the Atlantic.

\subsubsection{Stability of the overturning}

Observational estimates and ocean re-analyses indicate a negative $M_{o v}$ near the Atlantic southern boundary at $34^{\circ} \mathrm{S}$ within the range of -0.28 to $-0.05 \mathrm{~Sv}$ (see Mecking et al. 2017) suggesting a bi-stable $A M O C$ regime. However, half of the CMIP5 models used here have a positive $M_{o v}$ at $34^{\circ} \mathrm{S}$. The historical multi-model mean $M_{o v}$ at the southern Atlantic boundary is $+0.03 \pm 0.13 \mathrm{~Sv}$ implying that the CMIP5 ensemble is close to the cut-off point between mono- and bi-stability. Mecking et al. (2017), using a much larger number of climate models, showed that this common feature in CMIP5 is mainly due to a salinity bias, with most of climate models being too fresh near the surface and too saline at depth in the South Atlantic as compared to observations (Jackson 2013; Mecking et al. 2016, 2017). When the salinity bias is corrected, i.e. when $M_{o v}$ is calculated using the model current velocities but the observationally-based salinity vertical distribution, $M_{o v}$ became negative at the Atlantic southern boundary in most CMIP5 models in line with the observational estimates (Mecking et al. 2017).

Our results show that multi-model mean $M_{o v}$ at the southern boundary is reduced to (slightly) negative values in the RCP4.5 ( - 0.02 $\pm 0.11 \mathrm{~Sv})$ and RCP8.5 $(-0.05 \pm 0.10 \mathrm{~Sv})$ over the 21 st century, although multi-model standard deviation is still quite large. As $M_{o v}$ declines with the AMOC there is an anomalous salt import into the Atlantic and the highly increased net evaporation over the basin cannot be balanced by increasing freshwater transport convergence (mainly driven by $M_{a z}$ contribution). This results in a large salt content increase throughout the Atlantic basin which destabilises the $A M O C$ off-state (i.e. opposes the $A M O C$ weakening). It should be noted that $M_{o v}$ magnitude decreases in the North Atlantic subtropical region with the $A M O C$ in the first 50 years for both RCP scenarios but then starts to increase again to reach historical levels in RCP4.5 while it stabilises in the RCP8.5 multi-model mean (see Fig. 9).

A feedback mechanism which enhances the salinification of the North Atlantic, further destabilizing the $A M O C$ off state, is the southward shift of the ITCZ driven by the AMOC decline. This causes a reduction of precipitation, inducing an increased surface salinity in the tropical/subtropical North Atlantic (Mecking et al. 2016). Our results show that saltier waters are eventually transported in the subpolar region, increasing again salinities there after mid-century in both RCP scenarios, in spite of increasing surface freshwater flux.

These results enhance the likelihood of a mono-stable $A M O C$ regime against recent observational $M_{o v}$ estimates indicating bi-stability, although there is a quite large multimodel standard deviation with substantially different model responses, especially in RCP8.5. Coarse resolution in current coupled climate models and relatively large associated salinity and current velocity biases is probably a limiting factor in capturing variability in freshwater transports, especially at the southern boundary of the Atlantic. Recent long-term higher resolution (eddy-permitting) climate model simulations show a negative $M_{o v}$ at the southern boundary, supporting a bi-stability regime in line with observational estimates, that may maintain an $A M O C$ off-state for several centuries if freshwater input substantially increases over the northern North Atlantic (Mecking et al. 2016).

\subsubsection{Freshwater budget uncertainties in CMIP5}

As for the observational estimates, we need to stress here the caveats of climate model projections of Atlantic freshwater budget changes. CMIP5 models in their historical setting show important salinity biases as compared to observations (Mecking et al. 2017), around the southern boundary of the Atlantic in particular, which may strongly affect model $A M O C$-driven freshwater transports there. This is crucial for the model stability regime of the overturning, which in 
turn affects the sign of the salt advection feedback controlling long term-trends in the freshwater budget of the whole Atlantic Ocean.

There are also large uncertainties due to different representations of processes in the various CMIP5 models, which may strongly affect estimations of the anomalous freshwater budget. In particular, eddies, which are largely underestimated in coarse-resolution CMIP5 models, generally result in stronger ocean freshwater transports affecting the Atlantic freshwater budget (Mecking et al. 2016). Another important constraint is the representation of ice melting in CMIP5 models. Multi-year Greenland sea ice extent/volume strongly decreases in recent decades (van den Broeke et al. 2016) and it is also projected to decline further in the future (Fettweis et al. 2013). Although almost all CMIP5 models show a substantial decline in AMOC strength under RCP8.5 over the 21st century, Greenland ice sheet melting was either neglected or not explicitly represented in CMIP5 (Golledge et al. 2019). This, in turn, may result in the underestimation of future freshwater inputs and $A M O C$ decline by CMIP5 models, with strong implications for the changing Atlantic freshwater budget as assessed in this study. Golledge et al. (2019), using simulations of the Greenland ice sheet melting constrained by satellite-based measurements of recent changes in ice mass, showed that increasing meltwater from Greenland leads to a more drastic weakening of the $A M O C$ over the 21 st century.

The various uncertainties associated with CMIP5 models described above are also reflected in the quite large multimodel standard deviation for the surface freshwater flux and freshwater content change across the Atlantic obtained in this study (exceeding $50 \%$ of the mean in some regions). Moreover, variability in climate models is much less as compared to observations. In particular, interannual/decadal variability of surface freshwater fluxes and $A M O C /$ $F W T$ estimated by RAPID array measurements at $26.5^{\circ} \mathrm{N}$ (McDonagh et al. 2015; Smeed et al. 2018) is much higher as compared to CMIP5 model variations.

\section{Conclusions}

Observations over the last 40 years show that the water cycle and 3-D salinity spatial mean patterns are amplified in most regions of the Atlantic Ocean with the exception of the sub-polar region where a net precipitation decrease and upper layer salinification occur. The observational estimate of southward ocean freshwater transport increase at $26.5^{\circ} \mathrm{N}$ together with increasing net evaporation north of $26.5^{\circ} \mathrm{N}$ over the last few decades requires a large increase of southward freshwater transport at the Arctic/Atlantic boundary. However, although the Arctic has freshened over the last few decades there is insufficient evidence of increasing freshwater export to the Atlantic. In general, large uncertainties in all components of the freshwater budget make it particularly difficult to detect robust multi-decadal climatic trends. Moreover, the 40-year period considered here is relatively short in duration, so that natural variability may obscure long-term climatic trends, especially in the North Atlantic which is strongly affected by $A M O$ and $N A O$ interannual and decadal variability.

CMIP5 projections for both RCP4.5 and RCP8.5 scenarios clearly show that over the longer timescale, robust and strong trends in the atmospheric branch of the water cycle, ocean freshwater transport and ocean salinity emerge, as anthropogenic climate change progresses. Net evaporation is increasing in the sub-tropical regions and net precipitation is increasing in the North Atlantic sub-polar region over the 21 st century as the water cycle amplifies with warming. $A M O C$ substantially weakens reaching $~ 35 \%$ reduction in the CMIP5 multi-model mean under high warming RCP8.5 scenario. There is a small reduction in net precipitation and a dipole spatial pattern in the tropical Atlantic reflecting a southward shift of the ITCZ likely associated with an atmospheric response to $A M O C$ decline. Overall, the Atlantic Ocean is strongly drying over the 21 st century leading to increasing salinities almost throughout the basin. Results demonstrate that, under an intensifying atmospheric water cycle, southward ocean freshwater transport increases across the Atlantic basin. The magnitude of freshwater transport increases in spite of declining $A M O C$, as the long-term trend is mainly driven by changes in the gyre contribution to freshwater transport, which is in turn largely dominated by salinity change. Results demonstrate a strong salinification of the North Atlantic which cannot be balanced by freshwater transports, opposing further AMOC weakening.

Although climate model simulations under their current coarse resolution setting under-represent important processes and feedbacks in the global hydrological cycle and display a diverse range of solutions in terms of where $A M O C$, freshwater flux and salinity changes do occur, they broadly agree with observations and theoretical considerations in the emergence of an intensified water cycle and increasing ocean freshwater transports in the Atlantic Ocean under global warming. Increasing resolution and better representation of ice dynamics in climate models and enhanced continuous monitoring of the main components of the Atlantic freshwater budget would provide a better understanding of the complex processes and ocean/atmosphere feedback mechanisms governing the global hydrological cycle and overturning circulation.

Acknowledgements This work is part of the UK Natural Environment Research Council funded project CLimate scale analysis of Air and Water masses (CLAW). We acknowledge the World Climate Research Program's Working Group on Coupled Modeling, which is responsible for CMIP5, and we thank the climate modelling groups for producing 
and making available their model output. We acknowledge the Research Data Archive at the National Center for Atmospheric Research, Computational and Information Systems Laboratory, for making available the freshwater flux datasets.

Open Access This article is licensed under a Creative Commons Attribution 4.0 International License, which permits use, sharing, adaptation, distribution and reproduction in any medium or format, as long as you give appropriate credit to the original author(s) and the source, provide a link to the Creative Commons licence, and indicate if changes were made. The images or other third party material in this article are included in the article's Creative Commons licence, unless indicated otherwise in a credit line to the material. If material is not included in the article's Creative Commons licence and your intended use is not permitted by statutory regulation or exceeds the permitted use, you will need to obtain permission directly from the copyright holder. To view a copy of this licence, visit http://creativecommons.org/licenses/by/4.0/.

\section{References}

Belkin IM (2004) Propagation of the "Great Salinity Anomaly" of the $1990 \mathrm{~s}$ around the northern North Atlantic. Geophys Res Lett 31:L08306. https://doi.org/10.1029/2003gl019334

Broecker WS (1997) Thermohaline circulation, the Achilles heel of our climate system: will man-made $\mathrm{CO}_{2}$ upset the current balance? Science 278:1582-1588

Bryden HL, King BA, McCarthy GD (2011) South Atlantic overturning circulation at $24 \mathrm{~S}$. J Mar Res 69:38-55. https://doi. org/10.1357/002224011798147633

Byrne MP, Pendergrass GA, Rapp AD, Wodzicki KR (2018) Response of the intertropical convergence zone to climate change: location, width, and strength. Curr Clim Change Rep. https://doi. org/10.1007/s40641-018-0110-5

Carmack EC et al (2016) Freshwater and its role in the Arctic Marine System: sources, disposition, storage, export, and physical and biogeochemical consequences in the Arctic and global oceans. J Geophys Res Biogeosci 121:675-717. https://doi. org/10.1002/2015JG003140

Craig PM, Ferreira D, Methven J (2017) The contrast between Atlantic and Pacific surface water fluxes. Tellus A Dyn Meteorol Oceanogr 69(1):1330454. https://doi.org/10.1080/16000870.2017.1330454

Czaja A (2009) Atmospheric control on the thermohaline circulation. J Clim 39:234-247

Dai A, Qian T, Trenberth KE, Milliman JD (2009) Changes in continental fresh water discharge from 1948 to 2004. J Clim 22:2773-2792

de Vries P, Weber SL (2005) The Atlantic freshwater budget as a diagnostic for the existence of a stable shut down of the meridional overturning circulation. Geophys Res Lett 32(9):L09606. https:// doi.org/10.1029/2004GL021450

Diawara A, Tachibana Y, Oshima K, Nishikawa H, Ando Y (2016) Synchrony of trend shifts in Sahel boreal summer rainfall and global oceanic evaporation, 1950-2012. Hydrol Earth Syst Sci 20:3789-3798. https://doi.org/10.5194/hess-20-3789-2016

Dickson RR, Meincke J, Malmberg S, Lee AJ (1988) The "great salinity anomaly" in the northern North Atlantic 1968-1982. Prog Oceanogr 20:103-151

Drijfhout SS (2010) The atmospheric response to a thermohaline circulation collapse: scaling relations for the Hadley circulation and the response in a coupled climate model. J Clim 23(3):757-774. https://doi.org/10.1175/2009JCLI3159.1
Durack PJ, Wijffels SE (2010) Fifty-year trends in global ocean salinities and their relationship to broad-scale warming. J Clim 23:4342-4362

Durack PJ, Wijffels SE, Matear RJ (2012) Ocean salinities reveal strong global water cycle intensification during 1950 to 2000 . Science 336:455-458

Fettweis X et al (2013) Estimating the Greenland ice sheet surface mass balance contribution to future sea level rise using the regional atmospheric climate model MAR. Cryosphere 7:469-489

Forsberg R, Sørensen L, Simonsen S (2017) Greenland and Antarctic Ice Sheet mass changes and effects on global sea level. Surv Geophys 38:89-104

Friedman AR, Reverdin G, Khodri M, Gastineau G (2017) A new record of Atlantic sea surface salinity from 1896-2013 reveals the signatures of climate variability and long-term trends. Geophys Res Lett 44:1866-1876. https://doi.org/10.1002/2017GL072582

Garzoli SL, Baringer MO, Dong S, Perez RC, Yao Q (2013) South Atlantic meridional fluxes. Deep Sea Res Part I 71:21-32

Golledge RN et al (2019) Global environmental consequences of twenty-first-century ice-sheet melt. Nature 566:62-72

Good SA, Martin MJ, Rayner NA (2013) EN4: quality controlled ocean temperature and salinity profiles and monthly objective analyses with uncertainty estimates. J Geophys Res Oceans 118:67046716. https://doi.org/10.1002/2013JC009067

Haine TWN et al (2015) Arctic freshwater export: status, mechanisms, and prospects. Glob Planet Change 125:13-35. https:// doi.org/10.1016/j.gloplacha.2014.11.013

Hakkinen S, Rhines PB (2009) Shifting surface currents in the northern North Atlantic Ocean. J Geophys Res Oceans 114:C04005. https ://doi.org/10.1029/2008JC004883

Hegerl G et al (2015) Challenges in quantifying changes in the global water cycle. Bull Am Meteorol Soc 96:1097-1115

Held IM, Soden BJ (2006) Robust responses of the hydrological cycle to global warming. J Clim 19:5686-5699

Helm KP, Bindoff NL, Church JA (2010) Changes in the global hydrological-cycle inferred from ocean salinity. Geophys Res Lett 37:L18701

Holliday NP, Cunningham SA, Johnson C, Gary SF, Griffiths C, Read JF, Sherwin T (2015) Multidecadal variability of potential temperature, salinity, and transport in the eastern subpolar North Atlantic. J Geophys Res Oceans 120:5945-5967. https://doi. org/10.1002/2015JC010762

Huffman GJ, Adler RF, Bolvin DT, Gu G (2009) Improving the global precipitation record: GPCP version 2.1. Geophys Res Lett 36:L17808

Huisman SE, Den Toom M, Dijkstra HA, Drijfhout SS (2010) An indicator of the multiple equilibria regime of the Atlantic meridional overturning circulation. J Phys Oceanogr 40:551-567. https://doi. org/10.1175/2009JPO4215.1

Jackson L (2013) Shutdown and recovery of the AMOC in a coupled global climate model: the role of the advective feedback. Geophys Res Lett 40(6):1182-1188. https://doi.org/10.1002/grl.50289

Lauvset SK, Brakstad A, Våge K, Olsen A, Jeansson E, Mork KA (2018) Continued warming, salinification and oxygenation of the Greenland Sea gyre. Tellus A 70(1):1-9. https://doi. org/10.1080/16000870.2018.1476434

Li L, Schmitt RW, Ummenhofer CC, Karnauskas KB (2016) North Atlantic salinity as a predictor of Sahel rainfall. Sci Adv 2:e1501588

Lind S, Ingvaldsen RB, Furevik T (2018) Arctic warming hotspot in the northern Barents Sea linked to declining sea-ice import. Nat Clim Change 8:634-639

McDonagh EL, King BA, Bryden HL, Courtois P, Szuts Z (2015) Continuous estimate of Atlantic oceanic freshwater flux at $26.5^{\circ} \mathrm{N}$. J Clim 28:8888-8906. https://doi.org/10.1175/jcli-d-14-00519.1 
Mecking JV, Drijfhout SS, Jackson L, Graham T (2016) Stable AMOC off state in an eddy-permitting coupled climate model. Clim Dyn 47:2455-2470. https://doi.org/10.1007/s00382-016-2975-0

Mecking JV, Drijfhout SS, Jackson LC, Andrews MB (2017) The effect of model bias on Atlantic freshwater transport and implications for AMOC bi-stability. Tellus A 69(1):1299910. https://doi. org/10.1080/16000870.2017.1299910

Polyakov IV, Pnyushkov AV, Timokhov LA (2012) Warming of the Intermediate Atlantic Water of the Arctic Ocean in the 2000s. J Clim 25:8362-8370. https://doi.org/10.1175/JCLI-D-12-00266.1

Reagan J, Seidov D, Boyer T (2018) Water vapor transfer and nearsurface salinity contrasts in the North Atlantic Ocean. Sci Rep 8:8830. https://doi.org/10.1038/s41598-018-27052-6

Reverdin G, Friedman AR, Chafik L et al (2019) North Atlantic extratropical and subpolar gyre variability during the last 120 years: a gridded dataset of surface temperature, salinity, and density. Part 1: dataset validation and RMS variability. Ocean Dyn 69:385-403. https://doi.org/10.1007/s10236-018-1240-y

Richter I, Xie SP (2010) Moisture transport from the Atlantic to the Pacific basin and its response to North Atlantic cooling and global warming. Clim Dyn 35:551-566

Schanze JJ, Schmitt RW, Yu LL (2010) The global oceanic freshwater cycle: a state-of-the-art quantification. J Mar Res 68:569-595. https://doi.org/10.1357/002224010794657164

Schleussner C-F, Levermann A, Meinshausen M (2014) Probabilistic projections of the Atlantic overturning. Clim Change 127:579586. https://doi.org/10.1007/s10584-014-1265-2

Skliris N et al (2014) Salinity changes in the World Ocean since 1950 in relation to changing surface fresh water fluxes. Clim Dyn 43:709-736

Skliris N, Zika JD, Nurser G, Josey SA, Marsh R (2016) Global water cycle amplifying at less than the Clausius-Clapeyron rate. Sci Rep 6:38752. https://doi.org/10.1038/srep38752

Smeed DA, Josey SA, Beaulieu C et al (2018) The North Atlantic Ocean is in a state of reduced overturning. Geophys Res Lett 45:1527-1533. https://doi.org/10.1002/2017GL076350

Sohn BJ, Yeh SW, Schmetz J, Song HJ (2013) Observational evidences of Walker circulation change over the last 30 years contrasting with GCM results. Clim Dyn 40:1721-1732. https://doi. org/10.1007/s00382-012-1484-z

Stendardo I, Rhein M, Hollmann R (2016) A high resolution salinity time series 1993-2012 in the North Atlantic from Argo and Altimeter data. J Geophys Res Oceans 121:2523-2551. https:// doi.org/10.1002/2015JC011439

Stott PA, Sutton RT, Smith DM (2008) Detection and attribution of Atlantic salinity changes. Geophys Res Lett 35:L21702
Su T, Feng G (2015) Spatial-temporal variation characteristics of global evaporation revealed by eight reanalyses. Sci China Earth Sci 58(2):255-269. https://doi.org/10.1007/s11430-014-4947-8

Taylor KE, Stouffer RJ, Meehl GA (2012) An overview of CMIP5 and the experiment design. Bull Am Meteorol Soc 93:485-498

Terray L et al (2012) Near-surface salinity as nature's rain gauge to detect human influence on the tropical water cycle. J Clim 25:958-977

Trenberth K, Zhang R, National Center for Atmospheric Research Staff (Eds.) (2019) "The Climate Data Guide: Atlantic Multi-decadal Oscillation (AMO)." https://climatedataguide.ucar.edu/clima te-data/atlantic-multi-decadal-oscillation-amo. Accessed $10 \mathrm{Jan}$ 2019

van den Broeke MR, Enderlin EM, Howat IM, Kuipers Munneke P, Noël BPY, van de Berg WJ, van Meijgaard E, Wouters B (2016) On the recent contribution of the Greenland ice sheet to sea level change. Cryosphere 10:1933-1946. https://doi.org/10.5194/ tc-10-1933-2016

Wadley MR, Bigg GR (2006) Are "Great Salinity Anomalies" advective? J Clim 19:1080-1088. https://doi.org/10.1175/JCLI3647.1

Worthington EL, Frajka-Williams E, McCarthy GD (2019) Estimating the deep overturning transport variability at $26^{\circ} \mathrm{N}$ using bottom pressure recorders. J Geophys Res Oceans 124:335-348. https:// doi.org/10.1029/2018JC014221

Yu L (2011) A global relationship between the ocean water cycle and near-surface salinity. J Geophys Res 116:C10025. https://doi. org/10.1029/2010JC006937

Yu L, Weller RA (2007) Objectively analyzed air-sea flux fields for the global ice-free oceans (1981-2005). Bull Am Meteorol Soc $88: 527-539$

Zhang X et al (2007) Detection of human influence on twentiethcentury precipitation trends. Nature 448:461-465. https://doi. org/10.1038/nature06025

Zika JD, Skliris N, Blaker AT, Marsh R, Nurser AJG, Josey SA (2018) Improved estimates of water cycle change from ocean salinity: the key role of ocean warming. Environ Res Lett 13(7):1-10. https:// doi.org/10.1088/1748-9326/aace42

Publisher's Note Springer Nature remains neutral with regard to jurisdictional claims in published maps and institutional affiliations. 